\title{
Roles of Glia, Immune Cells and the Thermo-TRP Channels, TRPV1, TRPA1 and TRPM8, in Pathological Pain
}

\author{
Akio Hiura*,1 and Hiroshi Nakagawa $^{2}$ \\ ${ }^{I}$ Department of Oral Histology, School of Dentistry, ${ }^{2}$ Dentistry for Persons with Disability, Tokushima University Hos- \\ pital, University of Tokushima 3-18-15 Kuramoto cho, Tokushima 770-8504, Japan
}

\begin{abstract}
Studies into the interactions between glia/immune cells and neurons have focused on the induction of pathological (neuropathic or inflammatory) pain. Growing evidence of close relationships between peripheral and central glia and pathological pain has emerged during the last 2 decades. Numerous experimental studies have showed the release of cytokines and inflammatory neuropeptides from peripheral and central terminals of primary sensory neurons and from activated peripheral and central glia after nerve injury (crush, ligation or transection), which in turn act in a paracrine or autocrine manner. Cytokines induce the synthesis of algogens (pain-inducing substances such as prostaglandin) which leads to the primary (peripheral) or secondary (central) sensitization responsible for hyperalgesia or allodynia under inflammatory conditions. The review has also highlighted the role of thermo transient receptor potential (TRP) channels TRPV1, TRPA1 and TRPM8 in the induction of pathological pain. The noxious heat sensor TRPV1 has an overt role in noxious heat hyperalgesia or allodynia, whereas TRPA1 and TRPM8 seem to have roles in noxious cold or mechanical allodynia, although results are inconsistent. Close mutual interrelationships between immune and glial cells and thermoTRP channels via cytokines or pro-inflammatory neuropeptides cannot be ignored when attempting to explain the induction and continuation of pathological pain. Investigations on the initial signals sent to the central area (superficial dorsal horn) remote from injured (or infectious) sites are a key point to clarify the mechanisms of pathological pain.
\end{abstract}

Keywords: Chronic pain, glias, immune cells, thermoTRP channels, TRPV1, TRPA1, TRPM8.

\section{INTRODUCTION}

In this report, inflammation is used as a synonym of neuropathy; the former indicates the phenomena as a result of many kinds of the latter. Accordingly, pathological pain means both inflammatory and neuropathic pains.

Dubner and Gold [1] summarized the mechanisms of pain in the introduction to their paper "The Neurobiology of Pain" (National Academy of Sciences colloquium). They pointed to the complex mechanisms of pain, including 1) specialized receptors, 2) stimulus transduction mechanisms, 3 ) ion channel modulation, 4) rapid and slow activity involving excitatory and inhibitory transmitters and their receptors, 5) amplification (neuronal plasticity) of related signals depending on activity and signals at sites in the peripheral nervous system (PNS) and central nervous system (CNS), and 6) the distribution of environmental signals and their interactions with learned memories at higher centers (brain cortices). On the other hand, four-state-dependent sensory (pain) processing occurs in the somatosensory system [2]. The first state is responsible for the normal processing of low-(innocuous) and high-intensity peripheral stimuli (acute pain with tissue damage; a transient response to thresholdexceeding stimuli). The second is the activation of nociceptive C-fibers with sufficient intensity or duration to induce

*Address correspondence to these authors at the Department of Oral Histology, School of Dentistry, 3-18-15 Kuramoto cho, Tokushima 770-8504, Japan; Tel: +81-88-633-9121; Fax: +81-88-633-7342;

E-mail: hiuraaki@dent.tokushima-u.ac.jp rapid posttranslational changes in membrane-bound receptors of dorsal horn neurons, modifying their excitability (central sensitization). The third is activity-dependent changes in the expression of functional genes in dorsal root ganglions (DRGs) and dorsal horn neurons occurring several hours after noxious stimulation. The potentiation by gene transcription leads to an enhanced responsiveness to noxious stimuli for longer duration. The fourth sensory paradigm is induction by peripheral inflammation. In this fourth state, either low-intensity $\mathrm{A} \beta$ or $\mathrm{C}$-fiber inputs are considered to initiate central sensitization by sprouting. A combination of activity-dependent and signal molecule-mediated transcriptional and posttranslational changes occur in the primary sensory and secondary dorsal horn neurons (concomitant features of peripheral and central sensitization).

The foregoing assumptions are very important for the study of pain mechanisms even the present time, however, interactions between glial or immune cells and nociceptive neurons were not clearly described until now. Based on the previous reports, we attempted to reveal this point in the pathological (abnormal) pain, because there is mounting evidence of interactions between sensory neurons and peripheral or central glial cells via the reciprocal influences of cytokines, neuropeptides, and eicosanoids during pathophysiological conditions.

Pathological pain (hyperalgesia: acute or persistent pain induced by peripheral or central nerve injury, allodynia: pain induced by innocuous physical stimuli under normal conditions) can be caused by infections, damage, envenomation, 
and injury (including experimental axotomy) to the peripheral nerves or spinal cord. Sensitization can be categorized as peripheral or central. Peripheral sensitization involves a) the activation of peripheral nerve nociceptors (capsaicin receptors: TRPV1) and glial cells within DRGs, and b) a phenotypic switch in primary sensory neurons after the intraplantar injection of algogens (i.e., larger type DRG cells change to express substance $\mathrm{P}$ (SP) [3] or the capsaicin-receptor, vanilloid receptor 1 (VR1) [4]). Central sensitization involves the activation of microglia and astroscytes mainly in the spinal superficial dorsal horn underlying the interaction of immune cells and intrinsic neurons via cytokines, chemokines and neuropeptides. It also includes the activation of brain stem inhibitory neurons which descend to the spinal dorsal horn from the rostral ventromedial medulla (RVM), and indirectly stimulate secondary nociceptive neurons via the inactivation of inhibitory interneurons [5]. Accordingly, since this descending pathway tonically facilitates the spinal nociceptors, spinal cord transection and inactivation of the neurons in the RVM can reduce central sensitization (pain relief) [5].

Moreover, central sensitization may occur through the sprouting (structural organization) of large $\mathrm{A} \beta$ myelinated fibers into lamina II (the central terminating area of nociceptive C-fibers) in the spinal dorsal horn after nerve damage [6-8] or the topical application of capsaicin [9]. Thus, progressive tactile hypersensitivity in inflamed animals was thought to be due to sprouting of low threshold $\mathrm{A} \beta$ fibers which normally do not sense nociception [10]. Nerve growth factor (NGF) immunoreactive activation of microglia, a subset of astrocytes and putative Schwann cells in dorsal entry zones, was demonstrated in the injured area 1 to 2 weeks after spinal cord transection [11]. NGF released from these cells was assumed to promote the sprouting of primary afferents in the spinal dorsal horn after injury [11].

Several reviews specifically infer how central and peripheral glia (including mast cells [12-14]) is involved in the induction or propagation of neuropathic pain. Watkins and Maier [14] repeatedly stated the importance of interactions between immune cells (T-lymphocytes, macrophages, neutrophils, dendritic cells) including central glia (microglia), peripheral glia (satellite cells, Schwann cells), endothelium, fibroblasts and mast cells (immune and inflammatory cells), and central and peripheral neurons. Glia and immune cells release inflammatory cytokines (tumor necrosis factor, and interleukin-1,6) in response to pathological conditions [14]. Thus, neuro-immune interactions were stressed to participate in the development of peripheral neuropathies $[15,16]$. Immune suppressants such as cyclosporine A are thought to reduce neuropathic pain [15]. Complex regional pain syndrome (CRPS) I (reflex sympathetic dystrophy) and CRPS II (causalgia), mirror-image (uninjured side) pain and extraterritorial pain changes, and clinical back pain are explained by immune or autoimmune effects on the peripheral and central nervous system [14].

For the first time, a chronological description of the cytokines released from immune and glial cells under pathophysiological conditions is available for understanding the above interrelationships. Subsequently, capsaicin's noxious heat sensor TRPV1, and cool and cold TRP channels TRPA1 and TRPM8, respectively, should be taken into consideration for the induction of inflammatory pain and anti inflammatory pain.

\section{CYTOKINES, EICOSANOIDS AND THEIR CELL SOURCE}

\subsection{Cytokines and Eicosanoids}

Cytokines are chemical mediators produced in association with cell growth and differentiation as well as activation of the immune system and inflammatory responses $[17,18]$. Cytokines, their abbreviations and cell source are listed in Tables $\mathbf{1}$ and $\mathbf{2}$.

Several types of lipids known as signaling molecules act by binding to cell surface receptors. The most important of these molecules are prostaglandins (PG), prostacyclin, thromboxianes and leukotriens, known collectively as eicosanoids. They stimulate blood platelet aggregation, inflammation, and smooth-muscle contraction in target tissues. Due to their rapid degradation, they are believed to act locally via autocrine or paracrine signals. Eicosanoids are synthesized from arachidonic acid (AA) derived from membrane phospholipids. The first step in the synthesis of PG is the conversion of AA to prostaglandin $\mathrm{H}_{2}\left(\mathrm{PGH}_{2}\right)$ by cyclooxygenase (COX). Aspirin and other nonsteroidal anti-inflammatory drugs target this enzyme, thereby reducing inflammation and pain by inhibiting the synthesis of PG. Besides, PG stimulates cell proliferation and the development of cancer.

Increased PG synthesis is a specific response to acute and chronic inflammation. It is enhanced by a number of proinflammatory cytokines such as IL-1, TGF- $\beta$ and PDGF which are produced at injured sites. Production of IL-1 and IL-6 is

Table 1. Cytokines and Abbreviations

\begin{tabular}{|l|l|}
\hline \multicolumn{1}{|c|}{ Cytokines } & \multicolumn{1}{c|}{ Abbreviations } \\
\hline \hline interleukins & IL(interleukin)-1 $\alpha$, IL-1 $\beta$, IL-2 IL-15 \\
\hline chemokines & $\begin{array}{l}\text { IL-8/NAP (neutrophil activating protein)-1, NAP-2, MIP (macrophgeinflammatory protein, MCAF (monocyte chemotactic } \\
\text { and activating factor)/MCP (monocyte chemotactic protein)-1, MGSA (melanoma growth stimulatory activity), RANTES } \\
\text { (regulated upon activation normal expressed and secreted), TNF (tumor necrosis factor)- } \alpha, \beta, \text { IFN (interferon)- } \alpha, \beta, \gamma, G \\
\text { (granulocyte)- or M (macrophage)-CSF (colony stimulating factor) }\end{array}$ \\
\hline growth factors & $\begin{array}{l}\text { EGF (epidermal growth factor), FGF (fibroblast growth factor), PDGF (platelet-derived growth factor), TGF (transforning } \\
\text { growth factor)- } \alpha, \beta, \text { ECGF(endothelial cell growth factor), NT (neurotrophin)-3 6, GDNF (glial cell linederived neurotro- } \\
\text { phic factor), LIF (leukemia inhibitory factor = neuropoietins),CNTF (ciliary neurotrophic factor), OM (oncostatin M), IL-6 }\end{array}$ \\
\hline
\end{tabular}


Table 2. Cell Soruce of Cytokines Under Patholpgical Conditions

\begin{tabular}{|c|c|c|c|}
\hline Cell & \multicolumn{2}{|l|}{ Cytokines } & Conditions \\
\hline neurons & \multicolumn{2}{|l|}{ IL- $1 \beta$, IL-6, FGF, TGF- $\beta$} & peripheral infections, endotoxins, ischemia \\
\hline microglia & IL-2, NGF, FGF, PDGF, LT, NO, PLE & IL-1 $\beta$, IL-6, IL-8, & $\begin{array}{l}\text { PNS and CNS infections, brain injury, meningitis,multiple sclerosis, } \\
\text { Alzheimer disease, peripheralnerve ligation }\end{array}$ \\
\hline astroglia & \multicolumn{2}{|c|}{ IFN- $\gamma$, MIP-1, MIP-2, TNF- $\alpha, \beta$, TGF- $\beta$, PG } & \\
\hline lymphocytes & \multicolumn{2}{|l|}{ IL-1 $\beta$, IL-2, IL-6, TNF- $\alpha, \beta$, IFN- $\gamma$} & multiple screlosis \\
\hline macrophages & \multicolumn{2}{|l|}{ IL-1 $\beta$, IL-2, IL-6 } & Alzheimer disease \\
\hline endothelial cells & \multicolumn{2}{|l|}{ IL-1 $\beta$, IL-6, FGF, TGF- $\beta$} & ischemia \\
\hline mast cells & \multicolumn{2}{|l|}{ NGF, TNF- $\alpha$, NK-1, TT, IL-1, IL-6, HIS } & inflammation, injury \\
\hline
\end{tabular}

HIS : Histamine, LT : Leukotriens, NO : Nitric oxide, PG : Prostaglandin, PLE : Proteolytic enzyme, TT : Tryptase

suggested to be induced by the nonapeptide bradykinin (BK) and TNF- $\alpha$ in a hyperalgesic response. These cytokines primarily promote the production of prostaglandin, causing an increase in the transcription of enzymes, such as COX and phospholipase $\mathrm{A}_{2}\left(\mathrm{PLA}_{2}\right)$ [19]. One of the effects of prostaglandins $\mathrm{E}_{2}$ and $\mathrm{I}_{2}\left(\mathrm{PGE}_{2}, \mathrm{PGI}_{2}\right.$ : prostanoids) is to sensitize afferent fibers (peripheral sensitization) inducing pain.

Despite difficulty in confirming the passage of cytokines into the brain, increases in cytokine protein content and mRNA expression suggest that many cytokines are expressed within the brain and isolated cells of the CNS [17]. Immune cells are key candidates of the source of cytokines, because they are able to invade the brain after injury or inflammation [17]. However, since these myelomonocytic cells reach the brain a few hours after injury, early cytokines may be produced by cells within the brain [17]. The primary source of cytokines seems to be microglia, but the possibility of neurons, astroglia, and endothelial cells can not be excluded [17].

\subsection{Cytokine Receptors and the Role of Cytokines}

Receptors for IL-1, 2, 3, and 6, TNF- $\alpha$, and many growth factors are present in the brain especially the hypothalamus and hippocampus. Ligands such as IL-3 to IL-7, IL-9, GCSF, LIF and CNTF can bind to hematopoietic cytokinereceptors. Another member of this family is a $130 \mathrm{kD}$ glycoprotein (gp130) that couples with the binding proteins of IL6, IL-11, LIF, OM and CNTF. In the case of CNTF, LIF and OM receptors, the active receptor complex is formed by LIFreceptor $\beta$ chain (LIF-R $\beta$ ) together with gp130 [17]. Both gp130 and LIF-R $\beta$ act as signal transducers. They activate tyrosine kinases (Trk) within the cell, due to receptorcomplex formation triggered by the binding of cytokines.

The high-affinity neurotrophin receptors are for a family of Trk. Each Trk exhibits specific affinity, i.e., TrkA for NGF, TrkB for BDNF, and TrkC for NT-3. These receptors are widely distributed throughout the PNS and CNS. The low-affinity NGF receptor $\mathrm{p} 75$ is a member of a family that includes the TNF-receptors (type I and type II), CD30, CD40 (gene products responsible for apoptosis) [18] and the Fas (a member of the TNF receptor family, apoptotic factor) antigen receptor. Schwann cells and astrocytes also have numer- ous receptors for neuropeptides and cytokines. The many receptors on satellite glial cells (SGC) in DRGs or trigeminal ganglions (TGs) have been reviewed [20].

It is difficult to assess the effects of proinflammatory cytokines (IL-1 $\beta$ and TNF- $\alpha$ ) in normal brain tissue because of very low concentrations, regional differences, and a rapid turnover [20]. However, a role as modulators in sleep and feeding as well as proinflammatory mediators in normal brain function was stressed for IL- $1 \beta$ and TNF- $\alpha$ [21]. One of the physiological roles of cytokines is to maintain homeostasis, but excessive production can damage the body. Experimental evidence that cytokines can modulate systemic function by acting directly on the brain has been obtained by the injection of cytokines and their antibodies into the brain. These studies showed the aggravation and alleviation of pathological symptoms by cytokines and antibodies, respectively. Many cytokines and their receptors are distributed widely in the PNS and CNS [17]. Expression and activity levels of cytokines are increased under conditions of 'stress', such as chronic inflammatory disease, tumor growth, infection and trauma [17]. If extreme tissue trauma or systemic insults occur, cytokines excessively released from the injured tissue can enter the circulatory system [17]. As a result, acute and chronic production of cytokines at injured sites is considered a cause of pathological conditions.

Each member of the cytokine family can influence the peripheral and central nervous system, similar to the regulation of inflammatory and immune cells [17]. Peripherally produced IL-1 and TNF- $\alpha$ influence the brain indirectly, because they incite the production of IL-6 in various tissues [17]. Since centrally administered IL-1 increases the peripheral synthesis of IL-6, the central and peripheral production of cytokines may be regulated mutually [17].

\subsection{Effects of Cytokines in Experimental Conditions}

Subthreshold doses of TNF applied to injured or uninjured DRGs ipsilateral to ligated spinal nerve induced tactile allodynia, indicating a broader spinal sensitization (central sensitization) [22]. It is speculated that the applied NGF or up-regulated NGF production in areas inflamed due to injury directly affects peripheral nociceptors (TRPV1) and mast cells leading to the release of NGF, resulting in hyperalgesia 
to heat (peripheral sensitization) [23]. Up-regulation of $\mathrm{N}$ Methyl-D-Asparate (NMDA) receptors by $\mathrm{PKC}$, rous sarcoma virus's oncogene (Src), and an inflow of sodium ion was implicated in the central sensitization (post synaptic dorsal horn neuron), i.e., hyperalgesia or allodynia [24].

BDNF is a neurotransmitter or neuromodulator in small diameter nociceptive neurons. BDNF is synthesized in these neurons and packaged in dense core vesicles [25]. The BDNF-expressing nociceptive primary afferents terminate in the superficial dorsal horn (lamina I-II). The post synaptic neurons in the superficial dorsal horn express the TrkB receptor (a high-affinity receptor for BDNF). The intrinsic spinal neurons began to express c-fos and exhibited an increase in electrophysiological excitability on the application of BDNF in spinal cord preparations, but a reduction in nociceptive behavioral responses on the intrathecal (i.t.) administration of TrkB-IgG before the subcutaneous (s.c.) injection of formalin into hind paws [25]. Increased release of BDNF from central terminals of nociceptive afferents and TrkB expression in spinal neurons may occur in the dorsal horn under pathophysiological conditions (inflammation induced by injury). The potentiation of BDNF and TrkB enhances phosphorylation of the NMDA receptor, leading to the induction and maintenance of central sensitization [25].

The inflammatory peptide BK can sensitize nociceptors when stimulated by heat. BK activates both phospholipase $\mathrm{C}$ (PLC) and $\mathrm{PLA}_{2}$, thereby releasing potential intracellular signaling molecules (diacyl glycerol, inositol 1,4,5triphosphate: $\mathrm{IP}_{3}$ ) through hydrolysis of the inner plasma membrane phospholipid phosphatidylinositol 4,5bisphosphate $\left[\mathrm{PIP}_{2}\right.$ or $\left.\operatorname{Ptd} \operatorname{Ins}(4,5) \mathrm{P}_{2}\right]$, which in turn activate PKC and $\mathrm{Ca}^{2+}$-mobilization leading to the phosphorylation of heat receptors (for instance, the capsaicin receptor, TRPV1) [26]. Dephosphorylation by a calcium-dependent phosphatase, calcineurin, desensitizes the heat-activated or capsaicin-gated channel. Thus, the activity of the channel is regulated by phosphorylation and dephosphorylation [26]. $\operatorname{PKC} \gamma$ ( $\gamma$ isoform of PKC)-null mice showed no defect in terms of acute pain, comparable to wild-type mice [27]. In contrast, PKC $\gamma$-null mice showed a significant decrease of exaggerated responses (mechanical and thermal allodynia) to thermal and mechanical stimuli after partial sciatic nerve ligation [27]. It was concluded that partial nerve injury could not induce hyperexcitability of PKC $\gamma$ interneurons in the inner lamina II in PKC $\gamma$ null mice [27]. That is, $\mathrm{PKC} \gamma$ is likely to play a major role in persistent neuropathic pain. The role of proinflammatory cytokines (particularly, IL-1 $\beta$, IL-6, and $\mathrm{TNF}-\alpha$ ) in inflammatory pain was recently reviewed [28].

\subsection{Interactions of Neuropeptides and Cytokines be- tween Neurons and Glia}

Activated and reactive microglia in the CNS after partial peripheral nerve ligation are known to produce cytokines, such as PG, leukotriens, nitric oxide (NO), proteolytic enzymes and excitatory amino acids (glutamate or asparate). Substance P (SP, $10^{-10}-10^{-8} \mathrm{M}$ ) elicited the dose-dependent production of PGE as well as thromboxane $\mathrm{B}_{2}\left(\mathrm{TXB}_{2}\right)$, derivatives of $\mathrm{AA}$, via the actions of $\mathrm{COX}$ in cultured brain astrocytes from the rat [29]. Addition of the COX inhibitor indomethacin to astrocyte cultures after exposure to SP, reduced the production and release of PGE. The stimulatory effect of SP on PGE production was abolished by immunoadsorption of SP. Accordingly, the stimulatory effect of $\mathrm{SP}$ is clear in astrocytes.

Acting on metabotrophic receptors, glutamate stimulated the release of AA from brain (striatal) astrocytes extracted from the mouse embryo. In turn, AA seems to inhibit the uptake of glutamate into astrocytes, leading to potentiation of the NMDA-evoked current (excitation) in neurons [30]. That is, neurons and neighboring astrocytes are hot spots of the actions of AA [30].

An evidence has showed interaction between the $\mathrm{Ca}^{2+}$ dependent (elevation of $\mathrm{Ca}^{2+}$ levels) release of glutamate from astrocytes and signaling to neighboring neurons, thereby modulating neuronal activity [31]. In addition, it was demonstrated that astroglia can modulate synaptic transmission, in a high-resolution study of rat hippocampal neurons in culture [31]. Perisynaptic Schwann cells also modulate transmitter release at the frog neuromuscular junction. The neurotransmitters released from the synapses can spill over from the synaptic cleft and arrive at neurotransmitter receptors in adjacent astrocytes or perisynaptic Schwann cells, followed by an increase in the intracellular $\mathrm{Ca}^{2+}$ concentration in glial cells. The increase in $\mathrm{Ca}^{2+}$ levels incites the release of glutamate from glial cells, which feeds back to the presynaptic nerve terminals for the modulation of synaptic neurotransmission (decrease of glutamate: inhibition), i.e., via tripartite synapses [31].

Galanin, neuropeptide Y and calcitonin gene-related peptide (CGRP)-immunoreactivity were increased in nerve fibers, interneurons and glial cells in the gracil nucleus after chronic constriction injury (CCI) of the rat sciatic nerve [32]. Galanin, neuropeptide Y, and CGRP mRNA was not detected on the ipsilateral side of the gracil nucleus by in situ hybridization [32]. The increase in neuropeptides in the gracil nucleus was assumed to be derived from lumbar DRG cells after CCI, thereby allowing neuropeptides to be taken up by gracil neurons and glial cells [32].

\section{THE PARTICIPATION OF GLIA IN PATHOLOGI- CAL PAIN}

Relevant papers from the last decade are examined in this section. The participation of spinal cord microglia and astrocytes in hyperalgesia is a new and dramatic finding, because glia without axons in the CNS had not been believed to have any role in neuronal function [33]. Spinal dorsal horn glias are now known to be activated in response to s.c. inflammation, s.c. yeast cell walls, i.p. bacteria, peripheral nerve and spinal cord trauma (neuropathic conditions after nerve constriction or transection), bone cancer, and immune activation in the spinal cord, all of which incite hyperalgesia [33]. Namely, glial activation affects pathological pain rather than normal acute pain [33]. Activated glia (also mast cells [12]) release IL-1, IL-6 and TNF and these receptors are expressed in both neurons and glia $[12,33]$. These proinflammatory cytokines are thought to reinforce pain in the spinal cord [33]. 


\subsection{Glial Activation in Experimental Neuropathy}

Watkins et al., [34] studied the effects of several glial metabolic inhibitors [fluorocitrate (inhibitor of astrocyte activation), CNI-1493 (tetravalent guanylhydrazone compound, inhibitor of nitric oxide synthesis and cytokine), TNF-bp (binding protein, antagonist of TNF- $\alpha$ )] in hyperalgesic conditions (shortening of tail flick latency) after formalin (an algesic chemical) injections using the rat spinal cord. They found that fluorcitrate and CNI-1493 but not TNF-bp inhibited formalin-induced hyperalgesia, suggesting the participation of glia in the mediation of hyperalgesia. The role of IL-1, TNF- $\alpha$, and NO produced by glia was emphasized [34]. Mechanical allodynia was induced by partial ligation of the sciatic nerve (PSNL) in rats [35]. Allodynic behavior was closely associated with an enhancement of the immunoreactivity of complement receptor C3bi (OX42, marker for microglia), major histocompatibility complex II (OX6, marker for microglia) and glial fibrillary acidic protein (GFAP, marker for astroglial activation) in the superficial dorsal horn [35]. These results strongly suggested a role for glia in neuropathic pain.

Hyperalgesia is an acute phase response to a bacterial or viral infection, protecting the inner body through fever [36]. The administration of endotoxins (lipopolysaccharide etc.) or live bacteria elicits the release of proinflammatory cytokines (IL-1, IL-6 and TNF- $\alpha$ ) from various immune cells, leading to hyperalgesia. Neurotrophic viruses such as HIV-1 (causing AIDS) can cross the blood-brain barrier and activate microglia and astrocytes. Microglia and astrocytes recognize a glycoprotein (gp 120) expressed on the surface of HIV-1. Interestingly, i.t. application of gp 120 induced mechanical allodynia and hyperalgesia. Thus, the importance of spinal cord microglia and astrocytes to hyperalgesia and allodynia was stressed [36]. A subcutaneous injection of formalin $(5 \%$, $50 \mu \mathrm{l})$ into the hind paw of rats induced an increase of microglia and their activation on the ipsilateral side of the lumbar superficial dorsal horn and the gracil nucleus of the brainstem [37]. Cytokines, COX products, and NO released from activated microglia were suggested as serious inducers of neuropathic pain. IL- $1 \beta$-dependent $\mathrm{COX} 2$ induction and $\mathrm{PGE}_{2}$ release were demonstrated in the CNS of rats injected with complete Freund's adjuvant (CFA) into the hind paw [38]. The authors claimed that COX2 expression in the CNS following peripheral inflammation indicates a non-neuronal response, because the expression of $\mathrm{COX} 2$ mRNA in the lumbar spinal cord and $\mathrm{PGE}_{2}$ in the cerebrospinal fluid could not be eliminated after a complete sensory and motor conduction blockade of the sciatic nerve by bupivacaine [38]. Concomitantly, COX2 and the type-I IL- $1 \beta$ receptor were highly expressed, regardless of dorsal root rhizotomy, in neurons of lamina I-III of the dorsal horn ipsilateral to the inflamed paw [38].

Tight ligation of the lumbar spinal nerve induced an increase of FGF-2 and FGF-2 mRNA expression in the ipsilateral dorsal horn astrocytes [39]. The activated astrocytes and increase of FGF-2 in the dorsal horn paralleled the induction of mechanical allodynia 2 weeks after surgery, suggesting that FGF-2 is involved in the central sensitization after peripheral nerve injury [39]. Many studies have demonstrated that p38 MAP (mitogen activated protein) kinase is specifi- cally activated in hyperactive microglia in neuropathic pain models [40]. Enhanced pain behavior was reduced by pretreatment with inhibitors of $\mathrm{p} 38$ in the same experiments [40]. It was demonstrated in rats that ipsilateral glial cells (microglia and astrocytes) in the medullary superficial dorsal horn (MDH, lamina I-II) were activated following inferior alveolar nerve and mental nerve (V3) transection (IAMNT) associated with hyper tactile sensitivity (stimulation of whisker pads with a von Frey filament) [41]. The area of microglial activation was the same as the area of c-fos upregulation [41]. Since the number of TG neurons did not show a decrease, the authors concluded that the glial activation is due not to degenerative effects of the central terminals of primary afferents caused by the death of TG neurons but to the release of substances from the central terminals. Minocycline (inhibitor of microglial activation) reduced pain hypersensitivity after trigeminal nerve transection in parallel with a decrease in the phosphorylation of p38 MAPK and microglial activation [41]. Substances released from nociceptive central afferent terminals and /or MDH neurons were presumed to be the cause of glial activation (neuronal effects on central glia) [41]. It is important to note that the inducedarea of tactile hyperalgesia by IAMNT was the cutaneous sensory area (V2 region) of the maxillary nerve which was not injured in this experiment. This is very similar to the results of p38 activation in uninjured L4 and L5 DRG neurons after L5 ventral root transection [42]. AV 411 (ibudilast: 3-isobutyryl 1-2-isopropylpyrazole-pyridine, inactivating agent of glial cells) reduced mechanical allodynia induced by CCI of sciatic nerve and SNL (tight suture of L5 and L6 spinal nerves) in rats [43]. The efficacy of AV 411 was closely related to the decrease in immunoreactivity for GFAP in the lumbar spinal dorsal horn on the operated side [43]. The authors proposed using AV 411 for the clinical regulation of chronic pain.

Activation of phosphorylated Src-family (p-Src family) tyrosine kinases was demonstrated in OX42-immunoreactive microglia but not neurons and astroglia in the ipsilateral superficial dorsal horn after transection of the L5 spinal nerve in rats [44]. Src-family tyrosine kinases (SFKs) were estimated as having a close correlation with mechanical hypersensitivity but not thermal and cold hypersensitivity after spinal nerve injury, because of the alleviation of only mechanical hypersensitivity by 4-amino-5-7-pyrazol pyridine (PP2, inhibitor of SFKs) [44]. The activation of the Src family was suggested to increase the phosphorylation (p) of extracellular-regulated protein kinase (ERK), but not p38 MAPK (co-expression of p-ERK and p-p38: 33\%) in spinal microglia after nerve injury [44]. Thus, Src-ERK signaling was argued to be involved in nerve injury-induced mechanical hypersensitivity, separate from the p38 MAPK pathway. Curiously, selective motor fiber injury (L5 ventral root transection) led to the increased activation of p38 in uninjured ipsilateral L4 and L5 DRG neurons, and microglia (but not neurons) in the bilateral spinal dorsal horn [42]. The authors concluded that $\mathrm{p} 38$ activation via TNF- $\alpha$ synthesis is an initial marker for the induction of neuropathic pain (mechanical allodynia). However, the molecular mechanism (transmitting signals from injured fibers to intact DRG neurons and microglia) underlying injury-induced allodynia was not demonstrated in this study. 
Spinal cord injury to wild-type mice after a L5 spinal nerve transection induced the expression of $\mathrm{p} 38, \mathrm{TNF}-\alpha$, and NO synthetic enzyme (NOS) in the dorsal horn microglia, but failed to cause the expression of these cytokines in TLR (toll-like receptor) 2 knock-out mice [45]. TLR 2 on microglial cells was suggested to play an important role in the activation of nerve injury-induced p38 and the expression of TNF- $\alpha$ and NOS associated with hyperalgesia and mechanical allodynia [45]. TLRs are speculated to bind to endogenous molecules as well as pathogens, leading to inflammatory responses by innate immune cells upon bacteria and viral infections. SDSN (supernatant of damaged sensory neurons) extracted from F11 cells (a hybrid of mouse N18TG2 neuroblastoma cells and rat DRG neurons) by repeated freezing and thawing was used to stimulate microglial cells from both wild-type and TLR-knock-out mice [45]. Upon stimulation with SDSN, the mRNA expression of TNF- $\alpha$, IL- $1 \beta$, IL6 and inducible NOS (iNOS) increased in the wild-type microglia, but almost completely disappeared in the knock-out cells. These results indicate that TLR 2 mediates the effects of nerve injury factors (for instance, SDSN), leading to mechanical allodynia and thermal hyperalgesia [45]. Not only DRG cell damage but also nerve fiber injury triggered microglial activation in this study. Although the chemicals of SDSN are not shown, unknown substances released from damaged neurons were predicted as important inducers of neuropathic pain.

The relationship between thermal and mechanical hyperalgesia, and activation of spinal cord astrocytes and microglia was investigated by injecting Asian scorpion Butus martensi Karsch $(\mathrm{BmK})$ into the plantar hind paw of rats [46]. BmK induced thermal and bilateral mechanical hyperalgesia and early and late activation of microglia and astrocytes, respectively, suggesting the share of microglia and astrocytes in BmK envenomation-induced pain [46]. The activation of microglia and astrocytes in the ipsilateral superficial dorsal horn (L4-L5 spinal segment) and pain-related behavior were reduced by the i.t. injection of fluorocytrate or peritoneal injection of minocycline. From the time difference in activation between microglia and astrocytes, the latter was considered to contribute to the maintenance of bilateral mechanical hyperalgesia [46]. The therapeutic inhibition of glial activity in the spinal cord was stressed for the treatment of patients stung by scorpions [46].

The role of PNS (DRG) satellite glial cells (SGCs) in neuropathic pain was proposed based on recent experimental evidence [47]. Particularly, inhibition of glutamate recycling (accumulation of glutamate) in DRG cells caused by a decrease of glutamate transporters in the SGC after nerve injury and the activation of macrophages (equivalent to CNS microglia) were emphasized to explain the chronic neuropathy [47]. The authors recommended that pain induced by the activation of glia in both the PNS and CNS be termed "gliopathic pain".

\subsection{Morphological Changes to Glia after Nerve Injury}

Morphological changes of SGCs in L4 and L5 DRGs were reported after the transection of sciatic and saphenous nerves in mice, but hyperalgesic or allodynic behavior was not studied [48]. The formation of bridges between satellite cells ensheathing separate DRG cell bodies and development of new gap junctions were demonstrated, suggesting the induction of an enhanced pain state after peripheral nerve injury [48]. Dye coupling between SGCs and surrounding neurons showed a 6-fold increase in mouse DRG 2 weeks after sciatic nerve axotomy, also suggesting the formation of new gap junctions [20]. The movement of dye (true blue) from TG neurons to adjacent SGCs through connexons of gap junctions was demonstrated after the injection of capsaicin into the temporomandibular joint [49]. Neuron-glia signaling within TGs was thought to contribute to the development of peripheral sensitization through the transmission of inflammatory signals, as a result of migraines [49].

The mechanism of communication between neurons and SGCs is as yet unclear [20]. One review [50] inferred that astrocytes in the CNS can regulate presynaptic and postsynaptic maturation, including receptor density (increase or decrease) and the efficacy of transmitter release. Thus, the function of tripartite synapses, i.e., among presynaptic and postsynaptic neurons and astroglia, was suggested to be closely regulated by astrocytes [50].

To detect the changes of microglia in the CNS and DRGs after common peroneal nerve (CPN) ligation, transgenic mice with all microglia labeled by green fluorescence protein (GFP) were used in place of immunocytochemical methods [51]. Tactile allodynia (von Frey filament test to the point of bending over the dorsal hind paw) was induced in the ipsilateral hind paw following CPN injury. An increase and the activation of microglia (large cells with short, thick radiating processes) in the L4 segment were observed in the ipsilateral superficial dorsal horn (lamina I and outer part of lamina II) and ventral horn (lamina VII and IX) after CPN ligation [51]. Microglial activation was not seen in the CNS areas (anterior cingulated cortex, prefrontal cortex, primary and secondary somatosensory cortex, insular cortex, amygdala, hippocampus, periaqueductal gray, and rostral ventromedial medulla) following nerve injury. The contribution of microglia to chronic neuropathic pain is suggested to be related to that of spinal dorsal horn [51]. The authors speculated that microglia in the dorsal horn are activated by spontaneous excitatory signals from injured nerves rather than abnormal neuronal activity through injured nerve fibers [51]. A change of neither morphology nor density was found in the glial cells of the L4 DRG [51].

\subsection{Controversial Issues Regarding the Role of Glia in Neuropathic Pain}

Cannabinoids are known to inhibit pain through cannabinoid receptor-1 (CB1) located in the superficial dorsal horn. Strong CB1-immunoreactivity was demonstrated in lamia I and inner lamina II interneurons and astroglial processes other than pre- and postaxonal terminals of the dorsal horn, and smaller DRG neurons [52]. Therefore, astroglia were suggested to have an anti-hyperalgesic function [52]. In addition, McMahon et al., drew attention to controversy regarding inflammatory pain with microglial activation [40].

The causal relationship between mechanical (response to a single safety-pin prick to the plantar hind paw) and thermal pain behavior (applying acetone onto the plantar skin of the hind paw), and the density of primary afferent terminals, 
GABA-ir interneurons and astrocytes in the injured side spinal dorsal horn of rats were studied after partial or total tibial nerve ligation (TNL) [53]. The behavior was more severe after a partial TNL than total TNL. Numbers of SP-, CGRP-, and isolectin B4 (IB4)-positive fibers were reduced in the medial superficial layer (tibial zone) compared with the control after tibial nerve injury [53]. The number of activated astrocytes in the injured dorsal horn did not differ significantly between partial TNL $v s$. total TNL, and in TNL rats with or without pain behavior [53]. The decrease in the number and density of central primary afferent terminals and GABAergic interneurons, and the increase of GFAP-ir astrocytes and activated astrocytes were not associated with pain behavior. These results suggest that the increase of astrocytes and decrease of GABA-ir interneurons in the dorsal horn 7 days after injury is not necessarily correlated with mechanical allodynia [53].

A long-lasting increase of synaptic strength in spinal cord neurons (long-term potentiation: LTP) induced by high frequency stimulation (HFS) to the sciatic nerve was suggested to be related to the exaggerated pain behavior of the rats [54]. A significant increase in mRNA for IL- $\beta$, GDNF and iNOS in the lumbar ipsilateral spinal dorsal horn was demonstrated, although there was no significant increase in p38 MAPK, COX2 or TNF- $\alpha$ after HFS [54]. In contrast to previous reports [34, 37, 38, 41, 42, 45], the gene expression of p38 MAPK, COX2 and TNF- $\alpha$ did not seem to be important for spinal LTP by HFS [54].

The mechanisms of neuronal-glial communication and of the release of ATP, glutamate and other chemical messengers from glia in response to pathophysiological stimuli are yet to be defined [55]. Repetitive afferent inputs (caused by peripheral injury) increase the release of excitatory amino acids (glutamate) and peptides (SP or CGRP) from primary afferent terminals in the superficial dorsal horn, inducing the initial depolarization of dorsal horn neurons [32]. Sustained excitation serves to increase intracellular calcium levels, activating a variety of intracellular enzymes (COX2 and NOS) and PKC. Spinally released PGs and NO acutely enhance the subsequent release of afferent neuropeptides and glutamate. The activation of local kinases serves to phosphorylate membrane receptors and channels. Thus, Yaksh et al. [56] emphasized the sensitization of central terminals of C-fibers in the substantia gelatinosa of the dorsal horn as the key to hyperalgesia and allodynia induced by peripheral nerve injury, but did not refer to the role of CNS glia. In a recent report [57], the function of agrin (a single geneencoded sulfate proteoglycan which gather up various molecules ensuing specific functions) suppressing neuropathic pain (mechanical allodynia) through phosphorylation of the NMDA receptor (NR1 subunits) on GABA interneurons of the rat dorsal horn was demonstrated after sciatic nerve injury. Activation of GABA interneurons by NR1 phosphorylation was argued to inactivate the postsynaptic relaying neurons, consequently interrupting the pain. Unexpectedly, a decrease of the activation of glia did not suppress the allodynia [57].

Whether electrical or chemical transmission occurs in tripartite synapses is not clear at least in brain astrocytes [58]. As noted above, some results are controversial, with lines of evidence that glia and immune cells apparently affect neuropathic pain in the nervous system.

Both non-specific and specific (recognition of non-self substance) local immune responses to tissue damage, infection, or irritants cause inflammation [59]. The immune system ultimately initiates hyperalgesia, a ubiquitous form of defense against disease, in the vicinity of an injury [59]. The intraperitoneal administration of disease-inducing factors (pro-inflammatory cytokines, bacterial cell wall, killed bacteria, zymosan (yeast), tissue damage etc.) is able to generate hyperalgesia [59]. It is reasonable to think that hyperalgesia is a warning sign for protecting an injury from endogenous or exogenous attack to restore energy, mobilizing vital immune and nervous systems [59]. Therefore, inflammatory pain has a close correlation between the immune system and peripheral or central sensory systems.

\section{A PART OF TRP CHANNELS IN PATHOLOGICAL PAIN}

This section mainly deals with the receptors of 3 kinds of thermo TRP channels (TRPV1, TRPA1 and TRPM8) and intracellular pathways leading to produce the pathological pain.

\subsection{Capsaicin Receptor, TRPV1, and Neuropathic Pain}

The capsaicin receptor TRPV1 (transient receptor potential vanilloid 1), an ion channel, is the central generator of hyperalgesia [60] and an integrator of endogenous and exogenous signals [61]. Its regulatory mechanisms in intracellular signaling are complicated [61]. TRPV1 is a multimodal nocisensor able to sense heat, low $\mathrm{pH}$ (protons), and internal as well as external vanilloids [61] and allosterically modulated by pro-inflammatory mediators (PG, BK, ATP, 5-HT, NGF), enhancing the channel opening by heat, protons and capsaicin [60]. A pH lower than 6.4 (acidification) [62, 63] or higher than 8.0 (intracellular alkalization by $\mathrm{NH}_{4} \mathrm{Cl}$ ) [64] initiates tissue inflammatory conditions, lowering the threshold of TRPV1 to noxious stimuli. TRPV1-expressing peripheral terminals release various pro-inflammatory neuropeptides such as SP and CGRP, initiating neurogenic inflammation (vasodilation, plasmaextravasation) $[13,65,66]$.

Despite a profound loss of VR1 (former name of the capsaicin receptor TRPV1)-expressing C-fibers, capsaicininduced biting-licking behavior reappeared in mice with streptozotocin (STZ)-induced diabetes treated with capsaicin as neonates [67]. Surprisingly, capsaicin-insensitive A-fibers (large DRG neurons) expressed the capsaicin receptor VR1 in diabetic mice [67]. The authors considered that upregulation of VR1 expression on myelinated fibers accounts for the antihyperalgesic (analgesic) action of capsaicin cream in diabetic neuropathic pain [67]. By contrast, TRPV1positive nerve fibers showed a decrease in both sural nerve and skin biopsies from patients with painful diabetic neuropathies, implying no relation of TRPV1 to neuropathic pain [68].

Sensitization to TRPV1 by pro-inflammatory mediators (inflammatory soup) is believed to induce chronic pain (thermal hyperalgesia or allodynia) from normally innocuous stimuli $[69,70]$. TRPV1 null (deficient) animals have 
showed a dramatic reduction of thermal hypersensitivity (hypoalgesia) in inflammatory pain models $[69,71]$, but not in nerve-injury models [69]. The TRPV1null animals also behaved normally in response to innocuous and noxious mechanical stimuli $[69,71]$. From these findings, TRPV1 can potentiate a heat response under inflammatory conditions (low $\mathrm{pH}$ ), but does not function in response to thermal and mechanical stimuli in the case of injury [69].

Paradoxically, TRPV1 null mice showed normal responses to acute noxious heat [72-74]. Similarly, mice pretreated with capsaicin as neonates behaved normally when exposed to acute noxious heat [75-77]. Therefore, an acute noxious heat sensor other than TRPV1 was speculated to exist in primary afferent neurons $[78,79]$.

The larvae of mutant Drosophila painless flies showed a delayed response (hypoalgesia) to noxious heat $\left(48{ }^{\circ} \mathrm{C}\right)$, but a rapid response to temperatures above $52{ }^{\circ} \mathrm{C}$ similar to normal larvae [80]. The painless gene encodes a TRP ion channel. The authors hypothesized that TRP ion channels act as a common noxious heat sensor in both vertebrates and invertebrates, in other words "Nociception is to pain as phototransduction is to vision" [80], and "a separate pathway exists for moderate and intense noxious heat" $[80]$.

\subsection{The Actions of Agonists and Antagonists to TRPV1}

It was reported that both capsaicin and protons gate the TRPV1 channel [81]. Protons (low pH) potentiate the binding of capsaicin and promote opening of the channel, probably by binding directly to the open channel rather than capsaicin-binding sites [81]. A functional antagonist, ruthenium red (RR, TRPV1 channel blocker), failed to block noxious heat- and proton-induced firing but inhibited capsaicin's actions (sensitization to other noxious stimuli) in a study of ex-vivo saphenous nerve preparations of rats [62]; RR was able to prevent capsaicin's actions but not acute noxious heat. RR seems to bind the capsaicin-binding site but not interfere with proton binding, so it can not inhibit the firing induced by acidification. Thus, RR's inability to interfere with normal basal heat transduction is very similar to the behavior of TRPV1-deficient mice with no impairment of noxious heat sensitivity $[62,82]$.

Inflammatory mediators such as $\mathrm{BK}, 5-\mathrm{HT}$ and $\mathrm{PGE}_{2}$ induced sensitization (an inward membrane current) of cultured capsaicin-sensitive DRG neurons from newborn rats in acidic conditions (pH6.1) [83]. Since capsazepine (CPZ), an antagonist of capsaicin, inhibited such sensitization, it was suggested that the capsaicin receptor can function under inflammatory conditions [84]. The authors also implied that capsaicin and protons can gate the channel pore acting at the two different recognition sites on the same receptor protein [84]. CPZ reduced the hyperalgesic response (decrease in latency of hind paw's withdrawal in response to heat) caused by the pro-inflammatory mediator carrageenan without inhibition of paw edema. This indicates that the capsaicin receptor can function only in the nociceptive response underlying the presence of endogenous capsaicin-like ligands, but not in the effects of pro-inflammatory cells [84]; TRPV1 is not activated via inflammatory cells. CPZ competitively antagonized capsaicin's action but did not inhibit the action of protons, a candidate of an endogenous activator [84].
It was speculated that $\mathrm{CPZ}$ binds the vanilloid-binding pocket located in the TM (transmembrane) 3/4 region of the channel but does not induce allosteric change, and so does not block $\mathrm{Ca}^{2+}$ entry through the pore stimulated by low $\mathrm{pH}$ (5.0) [85]. Additionally, CPZ antagonizes nicotinic and voltage-gated calcium channels, i.e., it is not strictly selective of TRPV1 [86, 87]. Thus, the action of CPZ to TRPV1 is controversial: one, CPZ inhibits inflammation through TRPV1, while the other does not.

Acs et al., [88, 89] suggested the presence of two types of vanilloid receptor, i.e., high-affinity RTX (resiniferatoxin) binding (R-type) and low-affinity RTX binding (C-type). The discrepancy in normal response behavior to thermal noxious heat in TRPV1 null animals may be explained by the two distinct receptors. However, Szallasi and Blumberg [90] questioned such a notion, because the presumed two receptors seemed to show the mediation of either highaffinity RTX binding or low-affinity calcium uptake response in experiments using HEK293 cells transfected with VR1 cDNA. The activation of TRPV1 by ligands lowers the temperature threshold (hyperalgesia to heat), but the mechanisms of heat sensitivity are not clear [91]. It is worth keeping in mind that no selective inhibition of heat activation has been found in mutational studies [91, 92].

New TRPV1 antagonists (change of certain chemical radicals in CPZ) which effectively block the activation by capsaicin, protons and heat were reported to show more potent antagonism, have high specificity, and be competitive antagonists [93]. Wong and Gavva [93] classified TRPV1 antagonists into 4 categories (profile A to D) in which profile A antagonists block all modes of TRPV1 activation (capsaicin, $\mathrm{pH} \mathrm{5,} \mathrm{heat).} \mathrm{Profile} \mathrm{D} \mathrm{antagonists} \mathrm{block} \mathrm{activation} \mathrm{by}$ capsaicin, but in contrast potentiate the activation by both $\mathrm{pH}$ 5 and heat [93]. They demonstrated that profile A antagonists such as A-425619, AMG9810 and BCTC inhibited or reduced inflammation-induced hyperalgesia in rats, implying that the inhibition of all modes of TRPV1 activation is crucial for anti-hyperalgesia $[69,93]$. CPZ is classified in profile $\mathrm{B}$ because it blocks capsaicin and heat activation but not proton activation in rat TRPV1, and so can not antagonize inflammatory pain [93]. The different actions of each antagonist have attracted our considerable interest.

Despite that TRPV1 agonists such as the ultrapotent vanilloid RTX relieve pain through TRPV1 desensitization, they also induce nociceptive neuronal cell death, and so TRPV1 antagonists are potentially better drug candidates for pain treatment [93]. Quite recently, different clinical applications of vanilloid agonists for anti-nociceptive, antiinflammatory and anti-hyperalgesic effects via TRPV1 channels have been reported $[94,95]$.

\subsection{Sites of Action in the Molecular Structure of TRPV1 and TRP Complex in Modulating its Activity}

The amino acid residue aspartic acid (D) 646 in the pore region of TRPV1 was implicated as the binding site for RR due to the blocking of capsaicin's action [96]. Glutamic acid (E) 600 in the pore region was demonstrated as an important site generating a dynamic increase in heat-evoked current between $\mathrm{pH} 8$ and 6 [97] as well as responding to the thermal threshold above $43^{\circ} \mathrm{C}$. The TM6 inner-pore helix domain of 
TRPV1 [tyrosine(Y) 666-glycine (G) 683; particularly, threonine (T) 670 and alanine (A) 680] was suggested as a site of temperature-sensitive bending hinges [98]. The point mutation E648A in the extracellular region of oocytes showed a greater decrease in proton-activated current but not in capsaicin- or heat-evoked current, suggesting it to be a proton-mediated activation site [97]. The Y511A mutant in the cytosolic region near the TM 3 domain of the TRPV1 protein showed normal heat- and proton-evoked responses comparable to the wild type, although lacking significant capsaicin-sensitivity: the aromatic residue Y511 is critical for vanilloid-binding with the vanillyl moiety of capsaicin in rat and human TRPV1[61, 92, 99, 100]. Furthermore, Y511, methionine (M) 547, and T550 may be important molecular determinants of vanilloid-sensitivity [100]. Many TRPV1 agonists and antagonists are believed to bind overlapping sites, the so called vanilloid binding-pocket, within the TM3/4 region, but a few TRPV1 inhibitors such as RR bind to residues within the pore region (D646) [69, 96]. It was speculated that high extracellular concentrations of polyamines (spermine) at inflammatory sites could sensitize and permeate TRPV1 ion channels, indicating the important role of the pore region (D646 and E648) [101]. Recently the critical role of TRPV1 pore region was stressed for the species differences in block of the TRPV1 heat activation [102].

The signaling complex "transducisome" (TRP complex) derived from the Drosophila phototransduction machinery [103], which contains the TRP protein, scaffolding proteins such as PDZ (postsynaptic density protein, disc-large tumor suppressor, zonula occuludens protein) domains, receptors (Trk A, Trk B), enzymes (PLC, PKC) and $\mathrm{PIP}_{2}$, is very important to the TRP channel's function [102, 103]. Both phosphorylation of TRPV1 and hydrolysis of PIP $_{2}$ (removal from membranes) lower the heat threshold (hyperalgesia) [104]. Serine (S) 116, T144, T370 and S502 are PKAmediated phopsphorylation sites [91]. PKC-mediated and CaMKII $\left(\mathrm{Ca}^{2+}\right.$-calmodulin-dependent kinase)-mediated phosphorylation sites are S502 and S800, and S502 and T704, respectively [91]. S502 can be phosphorylated by all three kinases, representing a key residue in the excitation of sensory neurons [60]. Residues of TRPV1 detecting heat and modulating the heat threshold are likely spread within the channel [104].

There are three possible intracellular pathways to sensitize TRPV1 [105]: 1) promotion of TRPV1 phosphorylation by $\mathrm{PKC} \varepsilon$ through activation of bradykinin receptors $\left(\mathrm{B}_{1}, \mathrm{~B}_{2}\right)$ by bradykinin; 2) activation of TRPV1 via inactivation of $\mathrm{PIP}_{2}$ (hydrolysis) by PLC $\beta$ (however, there is controversy over recovery from desensitization or potentiation of TRPV1 by PIP $_{2}$ ) [106-108]; and 3) NGF's potentiation of TRPV1 via activation of PI3K (phosphoinositide 3-kinase) and tyrosine kinase Src, allowing phosphorylation of TRPV1 at Y200 and trafficking TRPV1 to the plasma membrane of the nociceptive neuron [107].

The scaffold protein AKAP (A kinase-anchoring protein) is known to target PKA, PKC and $\mathrm{Ca}^{2+}$-dependent phosphatase calcineurin on substrates [105]. The binding of PKA and PKC $\varepsilon$ to AKAP79 (human homolog)/150 (rat homolog), and in turn the binding of AKAP79/150 to the amino acid residues near the $\mathrm{C}$-terminal domain of the channel is thought to be crucial for the sensitization of TRPV1 [105]. In addition, AKAP150 was demonstrated as a major PKAanchoring protein participating in $\mathrm{PGE}_{2}-$ and PKAdependent TRPV1 modulation in mouse DRG neurons [109]. Moreover, it was demonstrated that AKAP coupled with $\mathrm{PIP}_{2}$ released from plasma membranes by PLC activation associate with TRPV1 in cell cultures of both chinese hamster ovary $(\mathrm{CHO})$ cells and trigeminal sensory neurons, and so regulating phosphorylation and sensitization of TRPV1 [110]. Namely, PLC-mediated sensitization of TRPV1 is dependent on AKAP150. The major mechanisms responsible for nociceptor sensitization can be summarized as follows [111]: 1) chemical modification of intracellular domains of TRPV1 by PK or phosphatases, and /or by hydrolysis of phosphoinositides contributes to greater channel activity, leading to sensitization, and 2) enhancement of TRPV1 expression in peripheral (or central) terminals of primary afferent neurons causes hyperalgesia.

For the induction of central sensitization in the substantia gelatinosa of the spinal dorsal horn, membrane-delimited coupling of TRPV1 with metabotropic glutamate receptor 5 (mGluR5) on the central presynaptic terminals of nociceptive neurons was suggested to have an important role associated with chronic pain [112].

Direct or indirect regulation of TRPV1 by endogenous factors was concisely reviewed by Marzo et al., [113]. PKA and PKC potentiate the gating of capsaicin receptors by noxious heat, protons (inflammatory condition), vanilloids and endovanilloid "anadamide (arachidonylethanolamide, AEA)" [113]. The thermal sensitivity of TRPV1 and capsaicinevoked response were reduced by $\mathrm{PIP}_{2}$, suggesting that endogeneous $\mathrm{PIP}_{2}$ modulates (inhibits) TRPV1 and that hydrolysis of $\mathrm{PIP}_{2}$ by PLC restores the actions of TRPV1 [114]; it was demonstrated that intracellular PLC signaling has a pivotal role in the hyperalgesia induced by two algesic agents, bradykinin and NGF [114]. The carboxy-terminal region near the proximal $\mathrm{C}$-terminal domain is known to interact with both $\mathrm{PIP}_{2}$ and calmodulin, indicating negative regulation (inactivation) of TRPV1 [115]. In contrast, dual effects of phosphoinositides [PIP ${ }_{2}$ or phosphatidylinositol-4phosphate: PIP] on TRPV1 were found depending on the stimulative force [116]; at a high concentration of capsaicin, phosphoinositides activate TRPV1 channels, and have no inhibitory effects, but at a low concentration of capsaicin or after a mild increase in temperature, they induce both inhibition and activation of the channels [116]. Phosphorylation of TRPV1 (activation) by PKA is emphasized for induction of heat hyperalgesia under inflammatory conditions [115]. Modulation of sensitivity in peripheral nociceptors via interaction between the SP receptor's neurokinin-1 (NK-1) and TRPV1 requiring $\mathrm{PLC} \beta$ and $\mathrm{PKC} \varepsilon$ (but not PKA) can lead to heat hyperalgesia being exaggerated after inflammation [117]. NK-1 activation leads to membrane trafficking of PKC $\varepsilon$, resulting in the potentiation of TRPV1 activity [117].

Despite the profound loss of L4 DRG small neurons and dorsal root unmyelinated fibers in mice treated with capsaicin as neonates ( 2 and 5 days of life), the animals behaved normally in response to noxious heat (hot plate: $55^{\circ} \mathrm{C}$, radiant heat) $[75,76]$, suggesting the presence of an unknown 
sensor beside capsaicin-sensitive, TRPV1-expressing DRG neurons in mice [77-79]. In this regard, recently it was reported that TRPV2 knockout or TRPV1/TRPV2 double knockout mice behaved normally to a broad range of noxious heat $\left(48-58{ }^{\circ} \mathrm{C}\right)$ even though in the peripheral inflammatory conditions [118]. TRPV2 expressed in medium- to large sized primary sensory neurons has long been believed to be activated by high threshold heat $\left(>52^{\circ} \mathrm{C}\right)$, however, it is not essential for heat and mechanical nociception [118].

\subsection{A putative Cold Sensor of TRP Channels, TRPA1, and Inflammatory Pain}

Initially, TRPA1 (transient receptor potential ankyrin 1, formerly known as "ANKTM1") was identified as the transformation-sensitive protein p120 extracted from cultured fibroblasts, which represents a novel TRP-like molecule with 18 ankyrine repeats in the N-terminal region within the cytoplasm and 6 transmembrane domains [119, 120]. Since TRPA1 is a nociceptive-specific ion channel gated by irritants and endogenous proinflammatory mediators, its inactivation would provide a new strategy for the treatment of coughing as well as inactivation of TRPV1 [121]. Cinnamaldehyde (CA, most specific TRPA1 agonist, ingredient of cinnamon oil) and BK could activate TRPA1, implying that TRPA1 is a polymodal nociceptor involved in BK-induced excitation, and in perceiving the burning pain sensation of cold [122]. Thus, TRPA1 has been thought to be required for the induction of neurogenic inflammation and pain hypersensitivity due to the activation of TRPA1 by BK, but not required for the initial detection of acute cold and auditorysensitivity [123]. Indeed, TRPA1-deficient mice showed reduced sensitivity to mustard oil and BK as well as to intense cold $\left(0{ }^{\circ} \mathrm{C}\right)$ and mechanical stimuli, therefore the contribution of TRPA1 to the sensing of acute cold and auditory stimulation remained to be elucidated [123]. The expression of TRPA1 was detected in the stereocilia of mouse inner and outer hair cells, suggesting its role as a mechanoreceptor and mechanonociceptor [124].

TRPA1 was found in a subset of small sensory neurons which also express TRPV1 (97\% ANKTM1-positive rat DRG neurons: TRPV1-positive) and the inflammatory peptide CGRP (97\% TRPA1-positive neurons: CGRP-positive) [120]. The proportion of TRPA1-expressing neurons was $56.5 \%, 36.5 \%$ and $28.4 \%$ in the adult mouse DRG, trigeminal ganglia and nodose ganglia, respectively, highly restricted to the smaller nociceptive neurons [125]. Upregulation of TRPA1 expression (ipsilateral: $29.5 \%$, contralateral: $17.2 \%$ ) was demonstrated in the ipsilateral L4 DRG neurons of rats after L5, L6 spinal nerve ligation (SNL) [125]. In parallel with the up-regulation of TRPA1 expression in a population of $\mathrm{A} \delta$-fibers, SNL-induced mechanical (von Frey) and cold $\left(6{ }^{\circ} \mathrm{C}\right.$ ) hyperalgesia were found in SNL rats [126]. Thus, TRPA1-expressing small DRG neurons and peripheral $\mathrm{A} \delta$-fibers are considered to be responsible for mechanical and cold allodynia.

TRPA1 exhibited a lower activation temperature (mean: $17.5^{\circ} \mathrm{C}$ ) than TRPM8 (transient receptor potential melastatin 8 , mean: $22.5{ }^{\circ} \mathrm{C}$ ), implying it to be a sensor for nociceptive cold [120]. Most allyl isothiocyanate (AITC: a TRPA1 agonist, the ingredient of mustard oil)-sensitive (TRPA1- expressing) mouse DRG neurons and mouse TRPA1expressing HEK293 cells responded to deep cooling (5-18 $\left.{ }^{\circ} \mathrm{C}\right)$ [127]. The probability of the TRPA 1 channel opening increased when the temperature decreased below $18{ }^{\circ} \mathrm{C}$, followed by an increase in whole-cell current induced by nociceptive cooling [127]. Conversely, TRPA1 was activated by mustard oil and tetrahydrocannabinoid (THC: cannabinoid receptor agonist), but not by noxious cold in cultured rat trigeminal neurons and TRPA1-expressing HEK293 cells, indicating its insensitivity to noxious cold [125, 128]. An interesting candidate for a cold nociceptor, TRPA1, was also activated by alkalization [129], although, the alkalization was suggested to induce acute pain rather than inflammation or hypersensitivity [129]. The injection of $15 \mathrm{~d}-\mathrm{PGJ}_{2}$ (15-deoxy- $\Delta 12$, 14-prostaglandin $\mathrm{J}_{2}$, a cyclopentane $\mathrm{PGD}_{2}$ metabolite) into the hind paw of wild-type and TRPA1deficient mice induced and failed to induce robust and acute nociceptive behavior, respectively [130]. These findings indicated that $15 \mathrm{~d}-\mathrm{PGJ}_{2}$ induced peripheral nociception through TRPA1, showing that TRPA1 is the principal receptor of $15 \mathrm{~d}-\mathrm{PGJ}_{2}$ in pain-sensing DRG neurons [130]. The expression of TRPA1 mRNA in GFR $\alpha 3$ (glycosylphosphatidylinositol anchored protein; binding protein for artemin, a neuronal survival factor in the GDNF family) -positive DRG neurons of ART-OE mice (transgenic overexpressing artemin in skin keratinocyte) was augmented in accordance with the increase of sensitivity to both heat and noxious cold [131]. The authors tentatively concluded that TRPA1 has an important role in the sensing of noxious cold and in nociceptive processing after inflammation [131]. Increased sensitivity to heat and mechanical stimuli was seen in both TRPA $1^{-1-}$ and TRPA $1^{+/+}$mice [132]. These studies indicated that although 4-HNE [4-hydroxynonenal as $\alpha, \beta$-unsaturated hydroxyalkenal (a product of lipid peroxidation accumulating in membranes under conditions of inflammatory and oxidative stress)] -induced cold allodynia is dependent on a functional TRPA1, but heathyperalgesia and mechanical allodynia are not [132]. As a consequence, the role of TRPA1 in cold allodynia was demonstrated in murine models of inflammatory and neuropathic pain [133].

CHO cells expressing human and rat TRPA1 were activated $\left(\mathrm{Ca}^{2+}\right.$-uptake assay) by AITC and cold $\left(3.5{ }^{\circ} \mathrm{C}\right)$ and inhibited by RR [134]. TCEB [trichrolo(sulfanyl)ethyl benzamides] compounds functioned as antagonists of TRPA1's activation by noxious cold and AITC [134]. AITC's induction of a consistent nociceptive response via the activation of TRPA1 was confirmed by a behavioral study in mice, and dependent on capsaicin-sensitive fibers, the release of histamine by mast cells and participation of tachykinine via neurokinin $1\left(\mathrm{NK}_{1}\right)$ receptors [135]. A tachykinin, substance $\mathrm{P}$, was suggested to activate both TRPV1 and TRPA1 receptors and thereby produce nociception [135]. Regardless of differences in chemical structure, several noxious substances (AITC, CA, etc.) operate via a common mechanism, the covalent attachment to specific cysteine residues in the long cytoplasmic $\mathrm{N}$-terminal domain of the TRPA1 channel [136].

It was reported that robust cold responses can occur in mouse DRG neurons from embryonic day 14.5 before the beginning of TRPM8 and TRPA1 expression, and CAsensitive cold $\left(5^{\circ} \mathrm{C}\right)$-responding neurons are few in number, 
suggesting an undefined role of TRPA1 in cold perception [137]. The hypothesis that TRPA1 is a cold transducer was not supported by experiments in which an agonist, CA, and antagonist, RR, were applied to the skin of anaesthetized rats [138]. Moreover, Reid [139] questioned the role of TRPA1 as a noxious cold sensor in vivo, implying that its responses to painful cold are likely to depend on sensitization. An increase of TRPV1 and TRPA1 expression in undamaged L4 DRG neurons was seen after L5 spinal nerve transection in the rat [44]. Since PP2 (inhibitor of SFKs) did not decrease the expression of TRPV1 and TRPA1 in L4 DRG, and heat and cold hypersensitivity after spinal nerve injury, respectively, SFKs are unlikely involved in the increase of TRPV1 and TRPA1 expression [44]. Accordingly, TRPV1 and TRPA1 probably do not participate in the hypersensitivity to cold and heat, but the activation of p-SFKs in microglia in the superficial dorsal horn ipsilateral to the L5 spinal nerve injury was suggested [44].

Extracellular signal-regulated protein kinase (ERK) and p38MAPK (family members of mitogen activated protein kinase) were differentially expressed in a subset of small to medium-sized rat DRG neurons [140]. Phosphorylation of ERK and p38 was found after noxious cold stimulation at $4^{\circ} \mathrm{C}$ in DRG neurons expressing either TRPA1 or TRPM8 mRNA, although, TRPA1 was mainly expressed in p38labeled neurons and TRPM8 expression was favored in ERK labeled neurons [140], indicating the different functional roles of TRPA1 and TRPM8 in sensing noxious cold [140]. 4-HNE and formaldehyde were found to be potent activators of TRPA1 [141]. TRPA1-deficient mice showed an impairment of the stimulation by these chemicals and noxious cold [141]. The evidence that mice pretreated neonatally with capsaicin did not show behavioral change (normal response) to painful cold $\left(1 \sim 2{ }^{\circ} \mathrm{C}\right)$ compared with the control mice might indicate the pivotal role of TRPA1-expressing DRG neurons [142].

From the effects of exogenous (formaldehyde) and endogenous (4-HNE) molecules on TRPA1 channels, TRPA1 was suggested to act as a "hub nociceptor" [143]. The injection of HNE into the hind paw of mice or rats induced painrelated behavior (licking or lifting the paw) and tactile allodynia [132]. Since these responses were not changed by CPZ treatment, the participation of TRPV1 was not considered in HNE-induced pain behavior [132]. Thus, TRPA1 is believed to be responsible for inflammatory pain via a distinct pathway from the TRPV1 channel. Mechanisms involved in inflammatory pain were suggested to be the result of the coactivation of multiple receptors [144]. For example, antagonists of either TRPA1 or H1 (histamine 1) or 5-HT (serotonin) receptors may be able to block formalin-induced nociception [144]. The co-expression of thermoreceptors (polymodal), TRPA1 with TRPV1, TRPM8 and tetrodotoxin (TTX)-resistant sodium channel Nav1.8 (known as nociceptors) channels in rat dental trigeminal afferent neurons suggested the transduction of tooth pain irrespective of hot or cold stimuli [145]. TRPA1, as one of the polymodal nociceptors, and its activation by proalgesic and possible intense cold, may play a crucial role in molecular integrating for noxious stimuli [86].
Variability of N-terminal with reducing ancestral thermosensibility for the specialized noxious chemical property of TRPA1 was thought to be necessary in the latest report [146].

Five factors are raised to estimate the above inconsistent experimental results and conclusions in understanding the physiological role of TRPA1 [147]; 1) Environmental differences between heterologus cells and naïve primary sensory neurons. 2) Differences of physiological relevance between sensory terminals and soma membrane channel expression. 3) Differences in physiological properties of TRPA1expressing cells from injured or inflamed tissue and intact areas. 4) Dissociated neurons may be injured during removal (axotomy). 5) Participation of different components in the response between single cells (in vitro) and animals (in vivo).

\subsection{Another Thermosensor, the TRPM8 Channel, as a Nocisensor}

For the first time, a novel trp-p 8 gene was identified and cloned by screening a prostate-specific subtracted DNA library [148]. Trp-p8 expression in human tissue is predominantly restricted to prostate epithelial cells, with overexpression in prostate cancer [148]. It also showed homology to human melastatin, a trp family protein expressed in melanocytes [148].

TRPM8 (a member of the melastatin subfamily) was found to be a cold- and menthol-sensitive receptor (CMR1) belonging to the long TRP channel subfamily [149]. Like TRPV1 neurons, small diameter trigeminal or DRG neurons of rats expressed CMR1 ( $50 \%$ of CMR1-expressing small cells: TRPV1-expressing cells) [149]. Therefore, CMR1expressing small sensory neurons were called "cold- and heat-sensitive nociceptors" [149]. At the same time, TRPM8, a group of TRPs characterized by a lack of ankyrin domains in the $\mathrm{N}$ terminus, was first named by Peier et al., [150] based on the suggestion that TRPM8 mediates $\mathrm{Ca}^{2+}-$ dependent, receptor-mediated excitation (pain signaling) and cell cycle progression [151]. It was reported that TRPM8 is a voltage-dependent channel (like TRPV1) activated by membrane depolarization and the cold sensitivity of TRPM8 is enhanced by low doses of menthol $(30 \mu \mathrm{M})$ independent of temperature $\left(24{ }^{\circ} \mathrm{C}, 34{ }^{\circ} \mathrm{C}\right)$ [152].

The first characterization of two distinct subpopulations of cold-responsive primary sensory neurons from adult rat trigeminal ganglia was made by Thut et al., [153]; one population comprises low threshold $\left(\mathrm{LT},>25^{\circ} \mathrm{C}\right.$ ) cold-responsive neurons (cool fibers) and the other, high threshold (HT, $<25$ ${ }^{\circ} \mathrm{C}$ ) cold-responsive neurons (C-cold nociceptors). TRPM8 was suggested to contribute to the cooling-induced activation of LT neurons, because LT neurons are similar to TRPM8expressing neurons in percentage (12.3\%), small cell diameter, activation threshold, capsaicin-insensitivity and responsibility to menthol [153]. On the other hand, HT neurons were thought to be activated by TRPM8 independently, because of an absence of menthol-sensitivity [153]. Likewise, HT cold $\left(20.3 \pm 0.8{ }^{\circ} \mathrm{C}\right)$-responsive neurons (in vitro) from rat trigeminal ganglia detected nociceptive cold via a TRPM8independent mechanism (TRPM8 expression: 9.4\%, menthol sensitive: $50 \%$, whereas LT neurons $\left(29.0 \pm 1.0{ }^{\circ} \mathrm{C}\right)$ sense 
cold dependent on TRPM8 (TRPM8 expression: 40\%, menthol sensitive: $70.8 \%$ ), suggesting the presence of two distinct populations of cold-responsive neurons in vivo [154]. A menthol-sensitive, TRPM8 cold-responsive receptor (18 \pm 1 ${ }^{\circ} \mathrm{C}$, average threshold: $26.5 \pm 0.7{ }^{\circ} \mathrm{C}$ ) determined by the specific blocking of its activation with BCTC [N-(4-tertbutylphenyl)-4-(3-chloropyridin-2-yl) piperazine-1-carboxiamide], was seen in neuronal soma of the mouse trigeminal ganglion and guinea pig corneal nerve terminals [155].

TRPM8 is specifically expressed in a subset $(5-10 \%)$ of small neurons of the adult mouse DRG, but not co-expressed with TPV1 [150]. It is activated by cold $\left(7-13{ }^{\circ} \mathrm{C}\right)$ and menthol (mimic the threshold temperature lowering), and distinct from the heat- and pain-sensing neurons expressing TRPV1, CGRP, and IB4 [150]. In contrast, major menthol-sensitive cells showed capsaicin-sensitivity (co-expression of menthol and capsaicin sensitivity) in the cultured rat DRG neuron $[149,156,157]$ even under conditions lacking NGF [155]. The authors explained the cold allodynia by suggesting the ectopic expression of cold sensitivity preferentially through TRPM8 in capsaicin-sensitive receptors. Moreover, noxious heat $\left(>44 \pm 0.35{ }^{\circ} \mathrm{C}\right)$ excited $65.1 \%$ of cooling-sensitive cells (menthol-sensitive, TRPM8-expressing cells) in the cultured DRG neurons of the rat [158]. That is, heat-activated TRPV1 excited cold-sensitive $\left(18{ }^{\circ} \mathrm{C}\right)$ cells identified by $\mathrm{Ca}^{2+}$ imaging and co-localization of TRPV1 in 29\% of TRPM8 cells by in situ hybridization. Okazawa et al., [158] explained the paradoxical cold sensation (noxious heat above $\sim 45{ }^{\circ} \mathrm{C}$ induced cooling) by the presence of cooling-/heat-sensitive small diameter primary afferent neurons.

Intriguingly, the hydrolysis of $\mathrm{PIP}_{2}$ via $\mathrm{PLC}$ activation leads to the down-regulation of TRPM8 expression by dephosphorylation but up-regulation of TRPV1 expression, suggesting the aggravation of inflammatory pain [159]. Although molecular mechanisms of the gating of thermo-TRP channels has not been precisely known to date, the modulatory role of the $\mathrm{C}$ terminal domain for the activation threshold on the channel open of TRPM8 and TRPV1 was demonstrated [160]. From studies of the exchange (chimeric channels) of the entire C-terminal domain between rat TRPV1 (heat receptor) and rat TRPM8 (cold receptor) using HEK293 cells, the C-terminal region of thermo TRP channels was stressed as a determinant (modulator) of temperature phenotype $[70,160]$. In addition, loss or single point mutation of the C-terminal coiled-coil domain distal to the last TM6 domain diminishes or depletes TRPM8's action [161].

Group I mGluR antagonists [162] and group II or III mGluR agonists were found to attenuate the development of mechanical or cold allodynia [163-165] and c-fos expression in the superficial dorsal horn neurons [162] associated with CCI- and formalin [163-165]- or capsaicin- and glutamate [162]-induced neuropathic pain. A novel finding was that TRPM8-expressing DRG neurons could mediate icilin-, menthol- and moderate cooling-induced thermal and mechanical analgesia by acting on group II/III mGluRs, leading to inhibition of pain and behavioral algesia after chronic injury of the rat sciatic nerve [166]. Namely, in contrast to TRPV1 and TRPA1, TRPM8 has an analgesic effect through Group II/III mGluRs, but not opioid receptors. On the other hand, TRPM8 knockout mice showed a complete inhibition of neuropathy (CCI model)-, or inflammation-induced (CFA application) cold allodynia, supporting the role of TRPM8 in injury-induced allodynia [167].

Psychophysical studies of both TRPM8 and TRPA1 activation in human volunteers by the application of either $40 \%$ menthol or $10 \%$ CA showed that CA induced a burning pain, heat hyperalgesia (allodynia), cold hypoalgesia and axon reflex (neurogenic inflammation), whereas menthol evoked a pinprick and a cold sensation, and cold hyperalgesia (allodynia), but not axon reflex [168]. The authors concluded that TRPM8 and TRPA1 channels have remarkably different roles in the psychophysical pattern of heat and cold sensation: TRPA1 takes part in burning pain, heat allodynia and axon reflex, while TRPM8 in pinprick and cold allodynia.

Nilius and Voets [169] proposed the mirror image theory to explain warm and cool sensing; cold receptors (TRPM8) switch on upon cooling and concurrently off upon warming and vice versa. This theory is not likely to make clear the paradoxical cold sensation induced by noxious heat. Exceeding over-threshold stimuli of heat or cold would also stimulate cold or heat receptor, generating the paradoxical sensation.

Collectively, whereas the activation of glial or immune cells following tissue damage, inflammation, infection and envenomation releases many kinds of cytokines, resulting in potentiation of nociceptors in PNS or CNS with regard to pathological pain (Fig. 1), acute noxious pain (physiological) seems to be closely related to unknown nociceptors without TRPV1, and glias or immune cells.

\section{CONCLUSION}

Pathological pain is derived from peripheral and central sensitizations in which the thermosensors TRPV1, TRPA1 and TRPM8 have a pivotal role in response to noxious physical or chemical stimuli. The former includes the sensitization of peripheral nociceptive afferent terminals, the genetical switching (up-regulation of thermo TRP channels) of primary sensory neurons, and the activation of peripheral glia (Schwann or satellite cells). The latter includes the sensitization of secondary neurons in the superficial spinal dorsal horn, sprouting from $\mathrm{A} \beta$ primary afferents' central terminals and the activation of descending brain stem inhibitory neurons. Activation of glial and immune cells in both PNS and CNS are concurrent with the activation of nociceptive neurons via the release of cytokines and neuropeptides underlying their mutual influences on the generation and maintenance of pathological pain. The signals responsible for neuropathic or inflammatory pain transmit to neighboring glia or those in the spinal cord dorsal horn after peripheral nerve injury must be a key cause of chronic pain. The growth factors (PDGF, TGF- $\beta, \mathrm{CNTF}$, and FGF) produced in response to nerve injury by sensory neurons, Schwann cells, and inflammatory cells are believed to be important and are centripetally transported [17]. To answer the above questions, two processes were proposed [40]. The first is depletion of target-derived neurotrophic factors (a negative signal), and the second is production of injury-induced cytokines and chemokines (a positive signal). These two signals are implicated in the alteration of gene expression in sensory neurons which results in abnormal electrical activity for 




Fig .(1). Putative sequential phenomena relevance to pathological pain caused by tissue or peripheral nerve injury (referred to the References 28 and 172). Many kinds of receptors expressed on nociceptors, interneurons in SG, peripheral and central glial or immune cells (including mast cells) and the intracellular second messengers for generation of abnormal pain were not illustrated (see the Text). NMDAR: NMDA receptor, PLE: Proteolytic enzymes, RVM: Rostral ventromedial medulla.

pathological pain behavior [40]. The facilitation of glial antiinflammatory conditions (inactivation of glia) seems to be a more powerful approach to the therapeutic control of neuropathic pain [170] as to the accompanying pain on the contralateral side (mirror image neuropathy) as well [171]. In short, the activation of glial and immune cells is closely correlated with the sensitization of peripheral and central thermoTRP channels in chronic pain. The essential nature of pathological pain will be explained by interactions of thermoTRP channels and glial and immune cells. Studies on the chemical and molecular intracellular signal cascades in thermo TRP channels responsible for sensitization or desensitization to pathological pain are now underway.

\section{CONFLICT OF INTEREST}

None declared.

\section{ACKNOWLEDGEMENT}

The publication of this review was supported by Grantsin-Aids (KAKENHI, 22592289) from the Ministry of Education, Culture, Sports, Science and Technology, Japan.

\section{REFERENCES}

[1] Dubner R, Gold M. The neurobiology of pain. Proc Natl Acad Sci USA 1999; 96: 7627-730.

[2] Woolf CJ, Costigan M. Transcriptional and posttranslational plasticity and the generation of inflammatory pain. Proc Natl Acad Sci USA 1999; 96: 7723-30.

[3] Neumann S, Doubell TP, Lesile T, Woolf CJ. Inflammatroy pain hypersensitivity mediated by phenotypic switch in myelinated primary sensory neurons. Nature 1996; 384: 360-4.

[4] Amaya F, Oh-Hashi K, Naruse Y, Iijima N, Ueda M, Shimosato G. Tominaga M, Tanaka Y, Tanaka M. Local inflammation increases vanilloid receptor 1 expression within distinct subgroups of DRG neurons. Brain Res 2003; 963: 190-6. 
[5] Urban MO, Gebhart GF. Supraspinal contributions to hyperalgesia. Proc Natl Acad Sci USA 1999; 96: 7687-92.

[6] Woolf CJ, Shortland P, Coggeshall RE. Peripheral nerve injury triggers central sprouting of myelinated afferents. Nature 1992; 355: 75-8.

[7] Shortland P, Woolf CJ. Chronic peripheral nerve section results in a rearrangement of the central axonal arborizations of axotomized A beta primary afferent neurons in the rat spinal cord. J Comp Neurol 1993; 330: 65-82.

[8] Millan MJ. The induction of pain: an integrative review. Prog Neurobiol 1999; 57: 1-164.

[9] Mannion RJ, Doubell TM, Coggeshall RE, Woolf CJ. Collateral sprouting of uninjured primary afferent A-fibers into the superficial dorsal horn of the adult rat spinal cord after topical capsaicin treatment to the sciatic nerve. J Neurosci 1996; 16(16): 5189-95.

[10] Ma Q-P, Woolf CJ. Progressive tactile hypersensitivity: an inflammation-induced incremental increase in the excitability of the spinal cord. Pain 1996; 67: 97-106.

[11] Krenz NR, Weaver LC. Nerve growth factor in glia and inflammatory cells of the injured rat spinal cord. J Neurochem 2000; 74(2):730-9

[12] Tore F, Tuncel N. Anatomical and functional relationships between sensory nerves and mast cells. Antiinflamm Antiallergy Agents Med Chem. 2011; 10(1): 1200-17.

[13] Dux M, Rosta J, Jancsó G. Capsaicin-sensitive nociceptive innervation of the dura mater: implications for the pathomechanism of headache. Antiinflamm Antiallergy Agents Med Chem. 2011; 10(1): 31-42.

[14] Watkins LR, Maier SF. Beyond neurons: evidence that immune and glial cells contribute to pathological pain states. Physiol Rev 2002; 82: 981-1011.

[15] Bennett GJ. Does a neuroimmune interaction contribute to the genesis of painful peripheral neuropathies? Proc Natl Acad Sci USA 1999; 96: 7737-8.

[16] Moalem G., Tracy DJ. Immune and inflammatory mechanisms in neuropathic pain. Brain Res Rev 2006; 51: 240-64.

[17] Hopkins SJ, Rothwell NJ. Cytokines and the nervous system I: expression and recognition. Trends Neurosci 1995; 18(2): 83-8.

[18] Rothwell NJ, Hopkins SJ. Cytokines and the nervous system II: actions and mechanisms of action. Trends Neurosci 1995; 18(3): 130-6.

[19] Cooper AD. The Cell-A Molecular Approach. 2nd ed. Washington DC: ASM Press 2000.

[20] Hanani M. Satellite glial cells in sensory ganglia: from form to function. Brain Res Rev 2005; 48: 457-76.

[21] Vitkovic L, Bockaert J, Jacque C. Inflammatory cytokines: neuromodulators in normal brain? J Neurochem 2000; 74(2): 457-71.

[22] Schäfers M, Lee DH, Brors D, Yaksh TL, Sorkin LS. Increased sensitivity of injured and adjacent uninjured rat primary sensory neurons to exogenous tumor necrosis factor- $\alpha$ after spinal nerve ligation. J Neurosci 2003; 23(7): 3028-38.

[23] Shu X-Q, Mendell LM. Neurotrophins and hyperalgesia. Proc Natl Acad Sci USA 1999; 96: 7693-6.

[24] Yu X-M, Salter MW. Src, a molecular switch governing gain control of synaptic transmission mediated by $N$-methyl-D-asparate receptors. Proc Natl Acad Sci USA 1999; 96: 7697-704.

[25] Thompson SWN, Bennett DLH, Kerr BJ, Bradbury EJ, McMahon SB. Brain-derived neurotrophic factor is an endogenous modulator of nociceptive responses in the spinal cord. Proc Natl Acad Sci USA 1999; 96: 7714-8.

[26] Cesare P, Moriondo A, Vellani V, McNaughton PA. Ion channels gated by heat. Proc Natl Acad Sci USA 1999; 96: 7658-63.

[27] Basbaum AI. Distinct neurochemical features of acute and persistent pain. Proc Natl Acad Sci USA 1999; 96: 7739-43.

[28] Luo C, Xie R-G, Hu S-J. Pain alleviation in anti-inflammatory and anti-allergic conditions. Antiinflamm Antiallergy Agents Med Chem. 2011; 10(1): 43-51.

[29] Hartung H-P, Heininger K, Schäfer B, Toyka KV. Substance P and astrocytes of the cyclooxygenase pathway of arachidonic acid metabolism. FASEB J 1987; 2: 48-51.

[30] Stella N, Tencé M, Glowinski J, Prémont J. Glutamate-evoked release of arachidonic acid from mouse brain astrocytes. J Neurosci 1994; 14( 2): 568-75.

[31] Araque A, Parpura A, Sanzgiri RP, Haydon PG. Tripartite synapses: glia, the unacknowledged partner. Trends Neurosci 1999; 22(5): 208-15.
[32] Ma W, Bisby MA. Ultrastructural localization of increased neuropeptide immunoreactivity in the axons and cells of the gracil nucleus following chronic constriction injury of the sciatic nerve. Neuroscience 1999; 93(1): 335-48.

[33] Watkins LR, Milligan ED, Maier SF. Glial activation: a driving force for pathological pain. Trends Neurosci 2001; 24(8): 450-5.

[34] Watkins LR, Martin D, Ulrich P, Tracey KJ, Maier SF. Evidence for the involvement of spinal cord glia in subcutaneous formalin induced hyperalgesia in the rat. Pain 1997; 71: 225-35.

[35] Coyle DE. Partial peripheral nerve injury leads to activation of astroglia and microglia which parallels the development of allodynic behavior. Glia 1998; 23: 75-83.

[36] Watkins LR, Maier SF. Implications on immune-to-brain communication for sickness and pain. Proc Natl Acad Sci USA 1999; 96 : 7710-3.

[37] Fu KY, Light AR, Matsushima GK, Maixner W. Microglial reactions after subcutaneous formalin injection into the rat hind paw. Brain Res 1999; 825: 59-67.

[38] Samad TA, Moore KA, Sapirstein A, et al. Interleukin-1 $\beta$-mediated induction of COX-2 in the CNS contributes to inflammatory pain hypersensitivity. Nature 2001; 410: 471-5.

[39] Madiai F, Hussain SRA, Goettl VM, Burry RW, Stephens RL Jr, Hackshaw KV. Upregulation of FGF-2 in reactive spinal cord astrocytes following unilateral lumbar spinal nerve ligation. Exp Brain Res 2003; 148: 366-76.

[40] McMahon SB, Cafferty WBJ, Marchand F. Immune and glial cell factors as pain mediators and modulators. Exp Neurol 2005; 192: 444-62.

[41] Piao ZG, Cho IH, Park CK, et al. Activation of glia and microglial p38 MAPK in medullary dorsal horn contributes to tactile hypersensitivity following trigeminal sensory nerve injury. Pain 2006; 121: 219-31.

[42] Xu JT, Xin WJ, Wei XH, et al. p38 Activation in uninjured primary afferent neurons and in spinal microglia contributes to the development of neuropathic pain induced by selective motor fiber injury. Exp Neurol 2007; 204: 355-65.

[43] Ledeboer A, Liu T, Shumilla JA, et al. The glial modulatory drug AV 411 attenuates mechanical allodynia in rat models of neuropathic pain. Neuron Glia Biol 2006; 2: 279-91.

[44] Katsura H, Obata K, Mizushima T, et al. Activation of Src-family kinases in spinal microglia contributes to mechanical hypersensitivity after nerve injury. J Neurosci 2006; 26(34): 8680-90.

[45] Kim D, Kim MA, Cho IH, et al. A critical role of toll-like receptor 2 in nerve injury-induced spinal cord glial cell activation and pain hypersensitivity. J Biol Chem 2007; 282(20): 14975-83.

[46] Jiang F, Liu T, Cheng M. Spinal astrocyte and microglial activation contributes to rat pain-related behaviors induced by the venom of scorpion Buthus martensi Karch. Eur J Pharmacol 2009; 623: 5264.

[47] Ohara PT, Vit JP, Bhargava A. Gliopathic pain: when satellite glial cells go bad. Neuroscientist 2009; 15(5): 450-63.

[48] Pannese F, Ledda M, Cherkas PS, Huang TY, Hanani M. Satellite cell reactions to axon injury of sensory ganglion neurons: Increase in number of gap junctions and formation of bridges connecting previously separate perineuronal sheaths. Anat Embryol 2003; 206: 337-47.

[49] Thalakoti S, Patil VV, Damodaram S, et al. Neuron-glia signaling in trigeminal ganglion: implications for migraine pathology. Headache 2007; 47: 1008-23.

[50] Slezak M, Pfrieger FW. New roles for astrocytes: regulation of CNS synaptogenesis. Trends Neurosci 2003; 26(10): 531-5.

[51] Zhang F, Vadakkan KI, Kim SS, Wu LJ, Shang Y, Zhuo M. Selective activation of microglia in spinal cord but not higher cortical regions following nerve injury in adult mouse. Mol Pain 2008; 4: 116.

[52] Salio C, Doly S, Fischer J, Franzoni MF, Conrath M. Neuronal and astrocytic localization of the cannabinoid receptor-1 in the dorsal horn of the rat spinal cord. Neurosci Lett 2002; 329: 13-6.

[53] Lee JW, Siegel SM, Oaklander AL. Effects of distal nerve injuries on dorsal-horn neurons and glia: relationships between lesion size and mechanical hyperalgesia. Neuroscience 2009; 158: 904-14.

[54] Pedersen LM, Jacobsen LM, Mollerup S, Gjerstad J. Spinal cord long-term potentiation (LTP) is associated with increased dorsal horn gene expression of IL-1 $\beta$, GDNF and iNOS. Eur J Pain 2000; 14: $255-60$. 
[55] Fields RD, Stevens-Graham B. New insights into neuron-glia communication. Science 2002; 298: 556-62.

[56] Yaksh TL, Hua XY, Kalcheva I, Nozaki TN, Marsala M. The spinal biology in humans and animals of pain states generated by persistent small afferent input. Proc Natl Acad Sci USA 1999; 96: 7680-6.

[57] Cui J-G, Bazan NG. Agrin downregulation induced by nerve injury contributes to neuropathic pain. J Neurosci 2010; 30(45): 1528697.

[58] Smith K. Settling the great glia debate: Do the billions of nonneuronal cells in the brain send messages of their own? Nature 2010; 468: 160-2.

[59] Watkins LR, Maier SF, Goehler LE. Immune activation: the role of pro-inflammatory cytokines in inflammation, illness responses and pathological pain states. Pain 1995; 63: 289-302.

[60] Holzer P. The pharmacological challenge to tame the transient receptor potential vanilloid-1 (TRPV1) nocisensor. Br J Pharmacol 2008; 155: 1145-62.

[61] Cortright DN, Szallasi A. Biochemical pharmacology of the vanilloid receptor TRPV1. Eur J Biochem 2004; 271(10): 1814-24.

[62] Pierre MS, Reeh PW, Zimmermann K. Differential effects of TRPV channel block on polymodal activation of rat cutaneous nociceptors in vitro. Exp Brain Res 2009; 196: 31-44.

[63] Tominaga M, Caterina MJ, Malmberg AB, et al. The cloned capsaicin receptor integrates multiple pain-producing stimuli. Neuron 1998; 21: 531-43.

[64] Dhaka A, Uzzell V, Dubin AE, et al. TRPV1 is activated by both acidic and basic $\mathrm{pH}$. J Neurosci 2009; 29(1): 153-8.

[65] Szallasi A, Cortright DN, Blum CA, Eid SR. The vanilloid receptor TRPV1: 10 years from channel cloning to antagonist proof-ofconcept. Nature Rev 2007; 6: 357-72.

[66] Alawi K, Keeble J. The paradoxical role of the transient receptor potential vanilloid 1 receptor in inflammation. Pharamacol Ther 2010; 125: 181-95.

[67] Rashid H, Inoue M, Bakoshi S, Ueda H. Increased expression of vanilloid receptor 1 on myelinated primary afferent neurons contributes to the antihyperalgesic effect of capsaicin cream in diabetic neuropathic pain in mice. J Pharmacol Exp Ther 2003; 306(2): 70917.

[68] Lauria G, Morbin M, Lombardi R, et al. Expression of capsaicin receptor immunoreactivity in human peripheral nervous system and in painful neuropathies. J Peripher Nerv Syst 2006; 11: 262-71.

[69] Immke DC, Gavva NR. The TRPV1 receptor and nociception. Semin Cell Dev Biol 2006; 17: 582-91.

[70] Bandell M, Macpherson LJ, Patapoutian A. From chills to chilis: mechanisms for thermosensation and chemesthesis via TRPs. Curr Opin Neurobiol 2007; 17: 490-7.

[71] Mishra SK, Hoon MA. Ablation of TrpV1 neurons reveals their selective role in thermal pain sensation. Mol Cell Neurosci 2010; 43: $157-63$.

[72] Caterina MJ, Leffler A, Malmberg AB, et al. Impaired nociception and pain sensation in mice lacking the capsaicin receptor. Science 2000; 288: 306-13.

[73] Davis JB, Gray J, Gunthorpe MJ, et al. Vanilloid receptor-1 is essential for inflammatory thermal hyperalgesia. Nature 2000; 405: 183-7.

[74] Woodbury CJ, Zwick M, Wang S, et al. Nociceptors lacking TRPV1 and TRPV2 have normal heat responses. J Neurosci 2004; 24: 6410-5.

[75] Hiura A, Villalobos EL, Ishizuka H. Age-dependent attenuation of the decrease of $\mathrm{C}$ fibers by capsaicin and its effects on responses to nociceptive stimuli. Somatosens Mot Res 1991; 9(1): 37-43.

[76] Hiura A, Nakagawa H, Koshigae Y, Yoshizako A, Kubo Y, Ishizuka $\mathrm{H}$. Age-related changes in the response to thermal noxious heat and reduction of C-fibers by neonatal treatment with capsaicin. Somatosens Mot Res 1999; 16(2):115-21.

[77] Hiura A. Neuroanatomical effects of capsaicin on the primary afferent neurons. Arch Histol Cytol 2000; 63(3): 199-215.

[78] Nakagawa H, Hiura A. Capsaicin, transient receptor potential (TRP) protein subfamilies and the particular relationship between capsaicin receptors and primary sensory neurons. Anat Sci Int 2006; 81: 135-55.

[79] Hiura A. Is thermal nociception only sensed by the capsaicin receptor, TRPV1? Anat Sci Int 2009; 84: 122-8.

[80] Tracy WD Jr, Wilson RI, Laurent G, Benzer S. Painless, a Drosophila gene essential for nociception. Cell 2003; 113: 261-73.
[81] Ryu S, Liu B, Qin F. Low pH potentiates both capsaicin binding and channel gating of VR1 receptors. J Gen Physiol 2003; 122: 4561.

[82] Hiura A, Nakagawa H. An overview of the actions of capsaicin and its receptor, TRPV1, and their relations to small primary sensory neurons. Antiinflamm Antiallergy Agents Med Chem. 2011; 10: 29.

[83] Vyklicky L, Knotková-Urbancová H, Vitásková Z, Vlachová V, Kress M, Reeh PW. Inflammatory mediators at acidic $\mathrm{pH}$ activate capsaicin receptors in cultured sensory neurons from newborn rats. J Neurophysiol 1998; 79: 670-6.

[84] Kwak JY, Jung JY, Hwang SW, Lee WT, Oh U. A capsaicinreceptor antagonist, capsazepine, reduces inflammation-induced hyperalgesic responses in the rat: evidence for an endogenous capsaicin-like substance. Pain 1998; 86(2): 619-26.

[85] Gavva NR, Tamir R, Klionsky L, et al. Proton activation does not alter antagonist interaction with the capsaicin-binding pocket of TRPV1. Mol Phamacol 2005; 68(6): 1524-33.

[86] Cortright DN, Szallasi A. TRP channels and pain. Curr Pharm Des 2009; 15: 1736-49.

[87] Wang Y. The functional regulation of TRPV1 and its role in pain sensitization. Neurochem Res 2008; 33: 2008-12.

[88] Acs G, Lee J, Marquez VE, Blumberg PM. Distinct structureactivity relations for stimulation of ${ }^{45} \mathrm{Ca}$ uptake and for high affinity binding in cultured rat dorsal root ganglion neurons and dorsal root ganglion membranes. Mol Brain Res 1996; 35: 173-82.

[89] Acs G, Biro T, Acs P, Modarres S, Blumberg PM. Differential activation and desensitization of sensory neurons by resiniferatoxin. J Neurosci 1997; 17(14): 5622-8.

[90] Szallasi A, Blumberg PM. Vanilloid (capsaicin) receptors and mechanisms. Pharmacol Rev 1999; 51(2): 159-211.

[91] Pingle SC, Matta JA, Ahern GP. Capsaicin receptor: TRPV1. A promiscuous TRP channel. Handb Exp Pharmacol 2007; 179: 15571.

[92] Conway SJ. TRPing the switch on pain: an introduction to the chemistry and biology of capsaicin and TRPV1. Chem Soc Rev 2008; 37: 1530-45.

[93] Wong GY, Gavva NR. Therapeutic potential of vanilloid receptor TRPV1 agonists and antagonists as analgesics: recent advances and setbacks. Brain Res Rev 2009; 60: 267-77.

[94] Jancsó G, Dux M, Oszlács O, Sántha P. Activation of the transient receptor potential vanilloid-1 (TRPV1) channel opens the gate for pain relief. Br J Pharmacol 2008; 155: 1139-41.

[95] Jancsó G, Oszlács O, Sántha P. The capsaicin paradox: pan relief by an algesic agent. Antiinflamm Antiallergy Agents Med Chem. 2011; 10(1): 52-65.

[96] Garcia MC, Morenilla PC, Planells CR, Merinos JM, Ferrer MA. Identification of an aspartic residue in the P-loop of the vanilloid receptor that modulates pore properties. J Biol Chem 2000; 275(42): 32552-8.

[97] Jordt SE, Tominaga M, Julius D. Acid potentiation of the capsaicin receptor determined by a key extracellular site. Proc Natl Acad Sci USA 2000; 97(14): 8134-9.

[98] Susankova K, Ettrich R, Vyklicky L, Teisinger J, Vlachova V. Contribution of the putative inner-pore region to the gating of the transient receptor potential vanilloid subtype 1 channel (TRPV1). J Neurosci 2007; 27(28): 7578-85.

[99] Jordt SE, Julius D. Molecular basis for species-specific sensitivity to "hot" chili peppers. Cell 2002; 108: 421-30.

[100] Gavva NR, Klionsky L, Qu Y, et al. Molecular determinants of vanilloid sensitivity in TRPV1. J Biol Chem 2004; 279(19): 2028395.

[101] Ahern GP, Wang X, Miyares RL. Polyamines are potent ligands for the capsaicin receptor TRPV1. J Biol Chem 2006; 281(13): 8991-5.

[102] Papakosta M, Dalle C, Haythornthwaite A, et al. The chimeric approach reveals that differences in the TRPV1 pore domain determine species-specific sensitivity to block of heat activation. J Biol Chem 2011; 286(45): 39663-72.

[103] Vennekens R, Voets T, Bindels RJM, Droogmans G, Nilius B. Current understanding of mammalian TRP homologues. Cell Calcium 2002; 31(6): 253-64.

[104] Nagy I, Sántha P, Jancsó G, Urbán L. The role of vanilloid (capsaicin) receptor (TRPV1) in physiology and pathology. Eur J Pharmacol 2004; 500(1-3): 351-69. 
[105] Zhang X, Li L, McNaughton PA. Proinflammatory mediators modulate the heat-activated ion channel TRPV1 via the scaffolding protein AKAP79/150. Neuron 2008; 59: 450-61.

[106] Liu B, Zhang C, Qin F. Functional recovery from desensitization of vanilloid receptor TRPV1 requires resynthesis of phosphatidylinositol 4, 5-bisphosphate. J Neurosci 2005; 25(19): 4835-43.

[107] Stein AT, Ufret VCA, Hua L, Santana LF, Gordon SE. Phosphoinositide 3-kinase binds to TRPV1 and mediates NGF-stimulated TRPV1 trafficking to the plasma membrane. J Gen Physiol 2006; 128(5): 509-22.

[108] Lishko PV, Procko E, Jin X, Phelps CB, Gaudet R. The ankyrin repeats of TRPV1 bind multiple ligands and modulate channel sensitivity. Neuron 2007; 54: 905-18.

[109] Schnizle K, Shutov LP, Van Kanegan MJ, et al. Protein kinase A anchoring via AKAP150 is essential for TRPV1 modulation by forskolin and prostaglandin $\mathrm{E}_{2}$ in mouse sensory neurons. J Neurosci 2008; 28(19): 4904-17.

[110] Jeske NA, Por ED, Belugin S, et al. A-kinase anchoring protein 150 mediates transient receptor potential family $\mathrm{V}$ type 1 sensitivity to phosphatidylinositol-4,5-bisphosphate. J Neurosci 2011; 31(23): 8681-8.

[111] Planells-Cases R, Garcì-Sanz N, Morenilla-Palao C, FerrerMontiel A. Functional aspects and mechanisms of TRPV1 involvement in neurogenic inflammation that leads to thermal hyperalgesia. Eur J Physiol 2005; 451: 151-9.

[112] Kim YH, Park C-K, Back SK, et al. Membrane-delimited coupling of TRPV1 and mGluR5 on presynaptic terminals of nociceptive neurons. J Neurosci 2009; 29(32): 10000-9.

[113] Di Marzo V, Blumberg PM, Szallasi A. Endovanilloid signaling in pain. Curr Opin Neurobiol 2002; 12: 372-9.

[114] Chuang H-H, Prescott ED, Kong H, et al. Bradykinin and nerve growth factor release the capsaicin receptor from $\operatorname{PtdIns}(4,5) \mathrm{P}_{2}$ mediated inhibition. Nature 2001; 411: 957-62.

[115] Tominaga M, Tominaga T. Structure and function of TRPV1. Eur J Physiol 2005; 451: 143-50.

[116] Lukacs V, Thyagarajan B, Varnai P, Balla A, Balla T, Rohacs T. Dual regulation of TRPV1 by phosphoinositides. J Neurosci 2007; 27(26): 7070-80.

[117] Zhang H, Cang CL, Kawasaki Y, et al. Neurokinin-1 receptor enhances TRPV1 activity in primary sensory neurons via PKCE: a novel pathway for heat hyperalgesia. J Neurosci 2007; 27(44): 12067-77.

[118] Park U, Vastani N, Guan Y, Raja SN, Koltzenburg M, Caterina MJ. TRP vanilloid 2 knock-out mice are susceptible to perinatal lethality but display normal thermal and mechanical nociception. J Neurosci $2011 ; 31(32): 11425-36$.

[119] Jaquemar D, Schenker T, Trueb B. An ankyrin-like protein with transmembrane domains is specifically lost after oncogenic transformation of human fibroblasts. J Biol Chem 1999; 274(11): 732533.

[120] Story GM, Peier AM, Reeve AJ, et al. ANKTM1, a TRP-like channel expressed in nociceptive neurons, is activated by cold temperatures. Cell 2003; 112(6): 819-29.

[121] Watanabe H, Ohba T, Satoh K, Sano K, Shioya T, Ito H. TRPV1 and TRPA1 in pulmonary vagal afferents and their relations to airway sensitivity. Antiinflamm Antiallergy Agents Med Chem. 2011; 10(1): 18-30.

[122] Bandell M, Story GM, Hwang SW, et al. Noxious cold ion channel TRPA1 is activated by pungent compounds and bradykinin. Neuron 2004; 41(6): 849-57.

[123] Bautista DM, Jordt S-E, Nikai T, et al. TRPA1 mediates the inflammatory actions of environmental irritants and proalgesic agents. Cell 2006; 124: 1269-82.

[124] Kwan KY, Allchorne AJ, Vollrath MA, et al. TRPA1 contributes to cold, mechanical, and chemical nociception but is not essential for hair-cell transduction. Neuron 2006; 50: 277-89.

[125] Nagata K, Duggan A, Kumar G, García AJ. Nociceptor and hair cell transducer properties of TRPA1, a channel for pain and heating. J Neurosci 2005; 25(16): 4052-61.

[126] Zhou GJS, Carlton SM. Intact A $\delta$-fibers up-regulate transient receptor potential A1 and contribute to cold hypersensitivity in neuropathic rats. Neuroscience 2008; 154: 1054-66.

[127] Sawada Y, Hosokawa H, Hori A, Matsumura K, Kobayashi S. Cold sensitivity of recombinant TRPA1 channels. Brain Res 2007; 1160: $39-46$.
[128] Jordt SE, Bautista DM, Chuang HH, et al. Mustard oils and cannabinoids excite sensory nerve fibres through the TRP channel ANKTM1. Nature 2004; 427: 260-5.

[129] Fujita F, Uchida K, Moriyama T, et al. Intracellular alkalization causes pain sensation through activation of TRPA1 in mice. $\mathrm{J}$ Clin Invest 2008; 118(12): 4049-57.

[130] Cruz OL, Dhaka A, Heuermann RJ, et al. Cutaneous nociception evoked by 15-delta PGJ2 via activation of ion channel TRPA1. Mol Pain 2008; 4: 30-8.

[131] Elitt CM, McIlwrath SL, Lawson JJ, et al. Artemin overexpression in skin enhances expression of TRPV1 and TRPA1 in cutaneous sensory neurons and leads to behavioral sensitivity to heat and cold. J Neurosci 2006; 26(33): 8578-87.

[132] Trevisani M, Siemens J, Materazzi S, et al. 4-hydroxynonenal, an endogenous aldehyde, causes pain and neurogenic inflammation through activation of the irritant receptor TRPA1. Proc Natl Acad Sci USA 2007; 104(33): 13519-24.

[133] del Camino D, Murphy S, Heiry M, et al. TRPA1 contributes to cold hypersensitivity. J Neurosci 2010; 30(45): 15165-74.

[134] Klionsky L, Tamir R, Gao BX, et al. Species-specific pharmacology of trichloro(sulfanyl)ethyl benzamides as transient receptor potential ankyrin I (TRPAI) antagonists. Mol Pain 2007; 3: 39-49.

[135] Andrade EL, Luiz AP, Ferreira J, Calixto JB. Pronociceptive response elicited by TRPA1 receptor activation in mice. Neuroscience 2008; 152: 511-20.

[136] Caterina MJ. Sticky spices. Nature 2007; 445: 491-2.

[137] Hjerling LJ, AlQatari M, Ernfors P, Koltzenburg M. Emergence of functional sensory subtypes as defined by transient receptor potential channel expression. J Neurosci 2007; 27(10): 2435-43.

[138] Dunham JP, Leith JL, Lumb BM, Donaldson LF. Transient receptor potential channel $\mathrm{A} 1$ and noxious cold responses in rat cutaneous nociceptors. Neuroscience 2010; 165(4): 1412-9.

[139] Reid G. ThermoTRP channels and cold sensing: what are they really up to? Eur J Physiol 2005; 451: 250-63.

[140] Mizushima T, Obata K, Katsura H, et al. Noxious cold stimulation induces mitogen-activated protein kinase activation in transient receptor potential (TRP) channels TRPA1- and TRPM8-containing small sensory neurons. Neuroscience 2006; 140: 1337-48.

[141] Macpherson LJ, Xiao B, Kwan KY, et al. An ion channel essential for sensing chemical damage. J Neurosci 2007; 27(42): 11412-5.

[142] Hiura A, Ishizuka H. Effects of capsaicin on the responses to nociceptive cold and tail pressure in mice: changes of these responses with time after birth (Japanese with English abstract). J Med Sci Toho Japan 1994; 41(1): 8-17.

[143] Tai C, Zhu S, Zhou N. TRPA1: the central molecule for chemical sensing in pain pathway? J Neurosci 2008; 28(5): 1019-21.

[144] Fischer L, Tambel CH, Parada CA. Letters to neuroscience. TRPA1-mediated nociception. Neuroscience 2008; 155: 337-8.

[145] Park CK, Kim MS, Fang Z, et al. Functional expression of thermotransient receptor potential channels in dental primary afferent neurons. J Biol Chem 2006; 281(25): 17304-11.

[146] Kang K, Panzano VC, Chang EC, et al. Modulation of TRPA1 thermal sensitivity enables sensory discrimination in Drosophila. Nature 2012; 481: 76-80.

[147] Stucky CL, Dubin AE, Jeske NA, Malin SA, McKemy DD, Story GM. Roles of transient potential channels in pain. Brain Res Rev 2009; 60: 2-23.

[148] Tsavaler L, Shapero MH, Molkowski S, Laus R. Trp-p8, a novel prostate-specific gene, is up-regulated in prostate cancer and other malignancies and shares high homology with transient receptor potential calcium channel proteins. Cancer Res 2001; 61: 3760-9.

[149] McKemy DD, Neuhausser WM, Julius D. Identification of a cold receptor reveals a general role for TRP channels in thermosensation. Nature 2002; 416: 52-8.

[150] Peier AM, Moqrich A, Hergarden AC, et al. A TRP channel that senses cold stimuli and menthol. Cell 2002; 108: 705-15.

[151] Clapham DE, Runnels LW, Strübing C. The TRP ion channel family. Nature Rev Neurosci 2001; 2: 387-96.

[152] Voets T, Droogmans G, Wissenbach U, Janssens A, Flockerzi V, Nilius B. The principle of temperature-dependent gating in coldand heat-sensitive TRP channels. Nature 2004; 430: 748-54.

[153] Thut PD, Wrigley D, Gold MS. Cold transduction in rat trigeminal ganglia neurons in vitro. Neuroscience 2003; 119: 1071-83.

[154] Nealen ML, Gold MS, Thut PD, Caterina MJ. TRPM8 mRNA is expressed in a subset of cold-responsive trigeminal neurons from rat. J Neurophysiol 2003; 90: 515-20. 
[155] Madrid R, Donovan RT, Meseguer V, Acosta MC, Belmonte C, Viana F. Contribution of TRPM8 channels to cold transduction in primary sensory neurons and peripheral nerve terminals. J Neurosci 2006; 26(48): 12512-25.

[156] Babes A, Zorzon D, Reid G. Two populations of cold-sensitive neurons in rat dorsal root ganglia and their modulation by nerve growth factor. Eur J Neurosci 2004; 20: 2276-82.

[157] Reid G, Babes A, Pluteanu F. A cold- and menthol-activated current in rat dorsal root ganglion neurons: properties and role in cold transduction. J Physiol 2002; 545 (2): 595-614.

[158] Okazawa M, Inoue W, Hori A, Hosokawa H, Matsumura K, Kobayashi S. Noxious heat receptors present in cold-sensory cells in rats. Nurosci Lett 2004; 359: 33-6.

[159] Premkumar LS, Raisinghani M, Pingle SC, Long C, Pimentel F. Downregulation of transient receptor potential melastatin 8 by protein kinase C-mediated dephosphorylation. J Neurosci 2005; 25(49): 11322-9.

[160] Brauchi S, Orta G, Salazar M, Rosenmann E, Latorre R. A hotsensing receptor: C-terminal domain determines thermosensation in transient receptor potential channels. J Neurosci 2006; 26(18): 4835-40.

[161] Schindl R, Romanin C. Assembly domains in TRP channels. Biochem Soc Trans 2007; 35: 84-5.

[162] Jin YH, Takemura M, Furuyama A, Yonehara N. Peripheral glutamate receptors are required for hyperalgesia induced by capsaicin. Pain Res Treat 2012; 2012: 915706.

[163] Fisher K, Lefebvre C, Coderre TJ. Antinociceptive effects following intrathecal pretreatment with selective metabotropic glutamate receptor compounds in a rat model of neuropathic pain. Pahrmacol Biochem Behav 2002; 73: 411-8.

[164] Simmons RMA, Webster AA, Kalra AB, Iyengar S. Group II mGluR receptor agonists are effective in persistent and neuropathic pain models in rats. Pharmacol Biochem Behav 2002; 73: 419-27.

[165] Chen S-R, Pan H-L. Distinct roles of group III metabotropic glutamate receptors in control of nociception and dorsal horn neurons in normal and nerve-injured rats. J Pharmacol Exp Ther 2005; 312(1): 120-6.

[166] Proudfoot CJ, Garry EM, Cottrell DF, et al. Analgesia mediated by the TRPM8 cold receptor in chronic neuropathic pain. Curr Biol 2006; 16: 1591-605.

[167] Colburn RW, Lubin ML, Stone Jr DJ, et al. Attenuated cold sensitivity in TRPM8 null mice. Neuron 2007; 54: 379-86.

[168] Namer B, Seifert F, Handwerker HO, Maihöfner C. TRPA1 and TRPM8 activation in humans: effects of cinnamaldehyde and menthol. Neuro Rep 2005; 16(9): 955-9.

[169] Nilius B, Voets T. Channelling cold reception. Nature 2007; 448: 147-8.

[170] Milligan ED, Watkins LR. Pathological and protective roles of glia in chronic pain. Nature Rev Neurosci 2009; 10: 23-36.

[171] Milligan ED, Twining C, Chacur M, et al. Spinal glia and proinflammatory cytokines mediate mirror-image neuropathic pain in rats. J Neurosci 2003; 23(3): 1026-40.

[172] Dubner R, Basbaum AI. In: Wall PD, Melzack R, Eds. Spinal dorsal horn plasticity following tissue or nerve injury. New York: Churchill Livingstone 1994; p. 238.

(C) Hiura and Nakagawa; Licensee Bentham Open.

This is an open access article licensed under the terms of the Creative Commons Attribution Non-Commercial License (http://creativecommons.org/licenses/by-nc/3.0/) which permits unrestricted, non-commercial use, distribution and reproduction in any medium, provided the work is properly cited. 